\title{
Convergent evolution of niche structure in Northeast Pacific kelp forests
}

\author{
Samuel Starko ${ }^{1,2,3}$, Kyle W. Demes ${ }^{4}$, Christopher J. Neufeld ${ }^{3}$ \& Patrick T. Martone ${ }^{1,3}$ \\ ${ }^{1}$ Department of Botany \& Biodiversity Research Centre, University of British Columbia, \\ Vancouver, $\mathrm{BC}$ \\ ${ }^{2}$ Department of Biology, University of Victoria, Victoria, BC \\ ${ }^{3}$ Bamfield Marine Sciences Centre, Bamfield, BC \\ ${ }^{4}$ Simon Fraser University, Institutional Strategic Awards, Burnaby, BC
}

Keywords: Laminariales, Diversification, Phylogenetic community assembly, Functional morphology, Adaptive radiation, Niche partitioning, Wave action, Phylogenetic overdispersion

\section{Acknowledgements}

The authors would like to thank L.Campbell, L.Bailey, E.Creviston, K.James, A.Warren, M.Brophy, A.Danasel, M.Fass, J.Townsend, E.Hardy, E.Sadler, L.Gonzalez, J.Matsushiba, L. Liggan, R. Munger, and B. Radziej for help in the field, L.Gendall for assistance with visualization and E. Clelland, S. Gray and the rest of the BMSC staff for assistance with field logistics. This work would not have been possible without the field surveys conducted by L. Druehl and C. Elliot, with funding from Parks Canada. Funding for this project was provided by the Natural Sciences and Engineering Research Council (NSERC) in the form of a Discovery Grant (to PTM), and a Canadian Postgraduate Scholarship (to SS), as well as from the Killam Trust in the form of an Izaak Killam Pre-doctoral Fellowship (to SS). The use of laboratory equipment was also supported by the Canadian Foundation for Innovation in the form of a Leaders Opportunity Fund Grant (\#27431) to PTM. Research conducted in Pacific Rim National Park was done with permission from Parks Canada (Permit Numbers: PRN-2015-18843, PRN-2018-29480). Thanks also to Huu-ay-aht First Nations for allowing research on their lands. We thank Q. Cronk, S. Graham, C. Harley and H. Verbruggen for helpful feedback on an earlier version of this manuscript.

\section{Author contributions}

This manuscript represents a chapter of S.S.'s PhD dissertation. S.S. conceived of and designed the study. S.S., K.W.D, and C.J.N. collected the data, P.T.M. provided guidance and funding. S.S. conducted analyses and wrote the first draft of the paper. All authors contributed input into the final version of the manuscript. 


\section{Convergent evolution of niche structure in Northeast 2 Pacific kelp forests}

1. Much of the morphological and ecological diversity present on earth is believed to have arisen through the process of adaptive radiation. Yet, this is seemingly at odds with substantial evidence that niches tend to be similar among closely related species (i.e., niche conservatism). Identifying the relative importance of these opposing processes in different circumstances is therefore essential to our understanding of the interaction between ecological and evolutionary phenomena.

2. In this study, we make use of recent advances in our understanding of the phylogeny of kelps (Laminariales) to investigate niche evolution in one of the most important groups of benthic habitat-forming organisms on the planet. We quantify functional traits and use community sampling data from a kelp diversity hotspot to determine which traits are responsible for the habitat $(\beta)$ niche of kelps and whether they are labile or conserved across the kelp phylogeny.

3. We find that combinations of functional traits have evolved convergently across kelp subclades and that these traits are significant predictors of community structure. Specifically, traits associated with whole-kelp structural reinforcement and material properties were found to be significantly correlated with species distributions along a gradient of wave disturbance and thus predict the outcome of environmental filtering. However, kelp assemblages were made up of species that are more phylogenetically distinct than predicted from null models (i.e., phylogenetic overdispersion), suggesting that niche partitioning along this gradient of wave disturbance has been an important driver of divergence between close relatives.

4. These results collectively demonstrate that environmental filtering by waves plays an essential role in determining the habitat niche of kelps across local communities and further suggest that this community-level process can drive phenotypic divergence between close relatives. We propose that parallel adaptive radiation of kelp subclades has shaped the diversity and species composition of kelp forests in the Northeast Pacific and we discuss how evidence from the literature on incipient or ongoing speciation events support this hypothesis. 


\section{Introduction}

40 A major challenge among ecologists is to understand how community-level processes influence

41 the macroevolution of lineages (Webb et al. 2002, Emerson and Gillespie 2008, Gerhold et al.

42 2015). Local environmental gradients serve as the environmental context in which both

43 ecological and evolutionary processes occur and can thus serve as a starting point to address

44 this challenge. In the context of communities, stress and/or disturbance from the environment

45 can exceed the tolerances of some species, causing them to be excluded from certain

46 communities (e.g. van der Valk 1981, Menge and Sutherland 1987, Webb et al. 2002, Cornwell

47 and Ackerly 2009, Kraft et al. 2014). Thus environmental gradients can serve as "environmental

48 filters", resulting in communities of species that share phenotypic traits necessary to survive in

49 a particular environment (Reich and Oleksyn 2004, Swenson and Enquist 2007, Kraft et al. 2011,

50 2014, Enquist et al. 2015, Cavalheri et al. 2015, Ulrich et al. 2017). Over evolutionary timescales,

51 environmental gradients can influence the phenotypic evolution of community members by

52 serving as strong sources of selective pressure (Cavender-Bares et al. 2004a, Demes et al. 2013,

53 Gerhold et al. 2015). Thus, community assembly dynamics along environmental gradients

54 depend strongly on the interplay of these ecological and evolutionary processes. Yet,

55 disentangling the factors at play has been an ongoing challenge (Cavender-Bares et al. 2009).

56

57 Depending on the evolutionary history of the species pool and the evolutionary lability of

58 underlying phenotypes, we might expect very different patterns of relatedness among the

59 species found in local communities subject to environmental filtering. Many studies have found

60 that closely related species share similar phenotypes (Webb 2000, Webb et al. 2002, Silvertown 
61 et al. 2006a, Kraft et al. 2007) due to selection against phenotypic divergence ("niche

62 conservatism") or due to a lag caused by a shared ancestor and slowly evolving traits (Wiens

63 2008, Losos 2008). This pattern is remarkably common (Darwin 1859, Webb et al. 2002, Vamosi

64 et al. 2009), leading many researchers to assume that it is true, even in the absence of any

65 phenotypic data (see Gerhold et al. 2015 for a review). When phenotype and phylogeny are correlated, closely related species are often clustered in space because close relatives with

67 similar traits tend to experience similar outcomes from strong environmental filtering (Fig 1a;

Webb et al. 2002, Cavender-Bares et al. 2009). However, the ubiquity of studies showing

evidence for niche conservatism stands in contrast to another body of work on the process of

70 adaptive radiations wherein lineages are known to spread out across environmental gradients

71 (hereafter "niche partitioning") to move into open niches as they diversify (MacArthur 1958,

72 Hector and Hooper 2002). This process would be expected to result in the opposite community

73 pattern: communities made up of distantly related species that share a set of convergently

74 evolved traits (Fig 1b; Cavender-Bares et al. 2004a, Silvertown et al. 2006a, 2006b, Cavender-

75 Bares et al. 2018). In order to reconcile this apparent disconnect between alternative

76 theoretical expectations of phylogenetic community structure, it is necessary to determine the

77 relative importance of these opposing evolutionary forces (niche conservatism versus niche

78 partitioning) in various lineages and circumstances to determine how and when particular

79 processes dominate phenotypic evolution. The relative importance of these different processes

80 can be inferred by identifying the patterns of phenotypic variation across the phylogeny of a

81 given lineage and by determining how this phenotypic variation relates to the sorting of species

82 into ecological communities (Lopez et al. 2016). 
84 While the relatedness of species within and between communities (hereafter, phylogenetic community structure) has been well explored in terrestrial taxa, particularly embryophytes

86 (Emerson and Gillespie 2008, Cavender-Bares et al. 2009), most marine lineages are poorly

87 studied in this respect (Verbruggen et al. 2009, Best and Stachowicz 2013). This is problematic because evolutionary processes in the ocean may be somewhat different from those on land,

89 with generally fewer barriers to reproduction in marine environments (Buzas and Culver 1991, Schluter 2000). Marine macroalgae offer an intriguing study system to explore the evolution of

91 phenotype and niche structure because morphologies, which are relatively simple, strongly

92 influence the abiotic tolerances of species (Littler and Littler 1984, Steneck and Dethier 1994,

93 Martone 2007, Starko and Martone 2016). In particular, water motion from waves and currents

94 is believed to act as an exceptionally strong environmental filter that excludes species from

95 more wave exposed sites if they are not strong enough to resist the forces that they experience

96 (Denny 1985, Gaylord et al. 1994, Denny and Gaylord 2002, Demes et al. 2013). Conversely, low

97 flow habitats may be highly stressful due to the formation of diffusive boundary layers that

98 reduce nutrient uptake and gas exchange across macroalgal thalli (Hurd 2017). Thus, low flow

99 environments may eliminate species that fail to achieve morphologies that facilitate the

100 depletion of boundary layers when water motion is low (Coyer and Roberson 2004). This

101 continuum of stress and disturbance caused by the position of local communities along

102 gradients of water motion is an essential driver of both community assembly processes and the

103 evolution of phenotypic traits across rocky shores, but ecological and evolutionary processes

104 have yet to be linked across any major lineage that occupies this environment. 
Kelps (order Laminariales) are the largest and most productive macroalgae in the ocean and

107 dominate approximately $25 \%$ of coastlines globally (Wernberg et al. 2019). Kelps increase the

108 productivity of cool, temperate nearshore ecosystems and their presence can substantially alter

109 the composition of biotic communities (Steneck et al. 2002, Graham 2004, Teagle et al. 2017,

110 Hind et al. 2019). In spite of their global importance, we still have a limited understanding of

111 the processes underlying the evolution of kelps. While recent advances in phylogenetics have

112 dramatically improved our understanding of the relationships between species and the

113 evolution of some key morphological features (e.g., Lane et al. 2006, Kawai et al. 2013, Jackson

114 et al. 2017, Starko et al. 2019b), it is unknown how niche structure has evolved across this

115 ecologically diverse clade. Kelps diversified in the North Pacific following the Eocene-Oligocene

116 boundary (Starko et al. 2019b), possibly as a result of ecological opportunity that arose as the

117 North Pacific cooled over the past 30 million years. While kelps are found globally, they are

118 overwhelmingly most diverse in the North Pacific and it remains largely unclear what processes

119 have allowed for the production of such high sympatric diversity in this part of the ocean.

121 In this study, we investigate the phylogenetic patterns of habitat $(\beta)$ niche structure across

122 geographically co-existing species of kelp in the Northeast Pacific, one of the most diverse

123 stretches of coastline for kelps and their likely center of origin (Starko et al. 2019b). We begin

124 by presenting a dataset of quantitative traits for 17 species of kelp and testing for phylogenetic

125 signals on these traits. We use an ancestral state reconstruction approach to determine

126 whether particular trait combinations share a common origin or whether they have 
127 convergently arisen in different subclades. Next, we test whether environmental filtering is an

128 important driver of community assembly and determine how this relates to the phenotypic and

129 phylogenetic structure of communities. We do so by making use of a community dataset that

130 spans a gradient of wave action, an important driver of nearshore community composition and

131 a known filter of the kelp species pool (Duggins et al. 2003, Burel et al. 2019). By teasing apart

132 the evolution of phenotypic features from patterns of phylogenetic community structure, our

133 results lend critical insights into the evolution of niche structure across one of the most

134 ecologically important groups of foundations species found anywhere in the ocean and shed

135 light on how ecological and evolutionary forces interact to shape marine communities.

137 Materials \& Methods

\section{Quantifying phenotypic traits}

139 Seven quantitative traits were compared for all kelp species of interest ( $n=17)$, many of which

140 are analogous to commonly measured traits in land plants; these included two traits describing

141 whole individual biomass allocation (stipe mass fraction or SMF, holdfast mass fraction or HMF)

142 and five traits describing mechanical and structural properties of blade tissues. SMF and HMF

143 describe the proportion of total biomass that is stipe or holdfast material, respectively. HMF is

144 analogous to root-shoot ratios in land plants. Organs (holdfast, blades, stipes) of individual

145 kelps ( $n=5$ per species) were carefully separated and dried in a $50-60^{\circ} \mathrm{C}$ drying oven. Blade

146 mass per area (BMA; analogous to leaf mass per area) was defined as the amount of dry

147 biomass per unit area of blade tissue and dry matter content (DMC) was defined as the ratio of

148 dry weight to wet weight. Both BMA and DMC were measured by taking hole punches of 
149 standardized area out of the blades and measuring the wet mass and dry mass of each hole

150 punch. Mechanical properties of blade material: breaking stress $(\sigma)$, stiffness $(E)$ and

151 extensibility $(\varepsilon)$, were measured using an Instron (model 5500R, Instron Corp., Canton,

152 Massachusetts, USA), a portable tensometer (described in Martone 2006), or were taken from

153 the literature (Tables S1-S2). With the exception of these few material properties

154 measurements taken from the literature, trait data represent average measurements taken

155 from adult individuals of populations in southern British Columbia (Barkley Sound, Port

156 Renfrew, Vancouver or Victoria; see Tables S1-S2). We used a principal components analysis to

157 collapse trait combinations into fewer axes of correlated traits. Then, to determine whether any

158 major PCA axis correlates with the ability of kelps to resist dislodgement, we tested for

159 correlations, using PGLS models, between PCA axes and tenacity-area scaling relationships

160 quantified previously (Starko and Martone 2016) for the 8 species included in that study.

161 Tenacity-area scaling relationships describe the slope of the relationship between maximum

162 dislodgement force and thallus size and are therefore an effective measure of wave tolerance.

165 The phylogeny of kelps, with more than 120 species, has been studied previously in

166 considerable detail (Lane et al. 2006, Jackson et al. 2017, Starko et al. 2019b). In this study, the

167 time-calibrated phylogeny inferred by Starko et al. (2019b) was used to represent phylogenetic

168 divergence in millions of years for the 17 co-occurring Northeast Pacific kelp species of interest.

169 This time-calibrated phylogenomic analysis is the most well supported and comprehensive to date and included all 17 species except Laminaria setchellii, which was incorporated into the 
171 analysis by substituting it for L. digitata, which is not found in the northeast Pacific but was

172 included in the phylogenomic analysis. This substitution relies on the assumption that $L$.

173 setchellii has an equivalent divergence time from Laminaria ephemera as L. digitata, which is

174 well supported by previous work on intrageneric relationships between Laminaria species,

175 showing less than 1 million years difference in divergence time between $L$. ephemera and $L$.

176 setchellii vs. L. digitata (Rothman et al. 2017). Phylogenetic signal of traits was measured using

177 Blomberg's K (Blomberg et al. 2003) and Pagel's lambda (Pagel 1999). We also tested for

178 correlations between trait distance and phylogenetic distance using Mantel tests.

180 We used the software "StableTraits" (Elliot and Mooers 2014) to reconstruct ancestral values of

181 principal component axes and the traits and to model rates of phenotypic evolution.

182 "StableTraits" samples from a heavy-tailed distribution, therefore allowing for modelling of

183 traits under selection. We ran StableTraits for 10 million generations, sampling every 1000

184 generations. Results of these analyses were visualized using the contMap function in "phytools"

185 (Revell 2012).

187 Community dataset

188 To determine how trait or phylogenetic differences influence community assembly, we used a

189 community dataset of intertidal kelp distributions in Barkley Sound, British Columbia that was

190 published in a Parks Canada technical report (Druehl and Elliot 1996). Data from sites sampled

191 in 1995 ( $\mathrm{n}=87$ sites), the most extensive year of this survey, were combined into a data matrix.

192 This dataset included all of the species examined in the trait analysis except two (Laminaria 
ephemera and Cymathaere triplicata). Although a coarse categorical abundance measurement

194 is given in their report, only presence and absence data were used. At a subset of sites $(n=55)$

195 that could be located by photographs in the 1996 report, the upper limit of barnacles was

196 measured in the summers of 2018-2019 and these values were used as a continuous proxy for

197 wave exposure. The upper limit of barnacles is an effective proxy of wave run-up and is known

198 to increase in elevation at more wave exposed sites (Harley and Helmuth 2003, Neufeld et al.

199 2017). The upper limit of barnacles was measured by using a stadia rod and sight level, along

200 with tide predictions from Bamfield Inlet, Effingham Island or Mutine Point, depending on

201 proximity. A categorical measure of wave exposure provided by Druehl \& Elliot was used for

202 analyses of all 87 sites. Barnacle upper limit was significantly different between these wave

203 exposure categories (ANOVA: $F_{2,52}=19.5815, P<0.0001$ ) with significant differences between

204 all means (Tukey HSD < 0.05), suggesting that barnacle upper limits are an appropriate proxy

205 for wave exposure. Using the range of barnacle upper elevation data (that spanned

206 approximately 3 to $5.5 \mathrm{~m}$ above MLLWLT), we created a "wave exposure index" by subtracting

2073 meters from each measurement and then dividing by 2.5 (the approximate range of barnacle

208 upper limits), resulting in an index that varied from 0 to 1 . Although resurveys were conducted

209 at some of these sites, recent work demonstrated that kelp forests have been lost from several

210 of these sites, likely as a result of the 2014-2016 heatwave (Starko et al. 2019a). Thus, only

211 historical data were used to reconstruct niche structure before the large-scale degradation of

212 these kelp communities. 


\section{Quantifying species co-occurrence}

215 First, to determine whether non-neutral processes were required to explain the distribution of

216 species across communities, we tested whether our community matrix was significantly

217 different from randomly generated communities. We did so by comparing our observed

218 checkerboard score (i.e., c-score; Stone and Roberts 1990), a measure of association between

219 species pairs, to randomly simulated communities. In order to test for significant associations

220 between individual species, observed co-occurrence probabilities were calculated for each pair

221 of species and compared to a null expectation of species co-occurrence that was generated

222 using randomizations that considered only the number of sites at which each species was

223 found. In cases where species were expected to co-occur at less than one site, these species

224 pairs were excluded due to insufficient data. Deviations from expectations were measured

225 using a log response ratio of observed vs. expected outcomes, hereafter "co-occurrence index".

226 Calculated as:

$$
\text { Co }- \text { occurrence index }=\log _{10}\left(\frac{\text { observed }}{\text { Expected }}+1\right)
$$

228 where "Observed" refers to the actual number of co-occurrences in the community matrix, and

229 "Expected" refers to the number of sites that species were expected to be found together given

230 the null model. Species association analyses were corrected for false detection rate and were

231 considered significant when q-values were less than 0.05. In order to determine whether

232 phylogenetic distance or trait differences (first and second trait-derived principal components)

233 influenced the co-occurrence probability of species, linear regressions were fit between each

234 predictor (phylogenetic distance, PC1 distance and PC2 distance) and co-occurrence index. 
237 The relationship between species presence and wave exposure was measured in two ways

238 using the subset of sites $(n=57)$ for which continuous wave exposure (barnacle upper limit)

239 had been measured. This subset did not include any sites with S. latissima, which was therefore

240 excluded from these analyses. It also included only one observation of P. palmaeformis at one

241 of the most wave-exposed sites in our dataset. This species is well known to occur only on the

242 most wave exposed shores (Nielsen et al. 2006) and so this site was deemed representative of

243 the niche of $P$. palmaeformis. However, to better improve our estimate of average wave

244 exposure for this species, we measured the upper limit of barnacles at two sites on the nearby

245 outer coast (Cape Beale) that consistently have Postelsia palmaeformis populations. All three

246 sites were very high exposure (upper limit of barnacles: 5.2 - $5.8 \mathrm{~m}$ above MLLWLT). To assess

247 the relationship between traits and species' habitat use, average wave exposure was measured

248 for each species from all sites in which that species was present. A phylogenetic least squares

249 (PGLS) regression was then used to test for an effect of principal component axes and all seven

250 quantitative traits on average wave exposure. In order to further visualize differences in species

251 habitat use, the probability of species presence was plotted against wave exposure (i.e., the

252 upper limit of barnacles) as modeled using polynomial, binomial generalized linear models. This

253 modelling approach allows for an optimal wave exposure rather than forcing saturation. This

254 was done separately for members of the two subclades with the most species included here,

255 the families Arthrothamnaceae and Alariaceae. To determine whether sites of different wave

256 exposure also have different kelp communities, we conducted a PERMANOVA with the wave

257 exposure categories described above as a predictor variable. 
259 Phylogenetic community structure

260 To further test for an effect of phylogeny on community assembly we used indices of

261 phylogenetic community structure (Webb 2000). Net relatedness index (NRI) and nearest taxa

262 index (NTI) measure the extent to which taxa are phylogenetically clustered at a particular site

263 relative to the regional species pool. A positive value of either NRI or NTI indicates phylogenetic

264 clustering, while negative values indicate phylogenetic overdispersion. NRI measures

265 phylogenetic clustering by considering the average phylogenetic distance between all members

266 of a community. Specifically, NRI is defined as follows:

$$
N R I=-\frac{X_{n e t}-X_{n u l l}}{S D_{n e t}}
$$

268 Where $X_{n e t}$ is the average phylogenetic distance between members of a community, and $X_{\text {null }}$

269 and $\mathrm{SD}_{\text {null }}$ represent the mean and standard deviation, respectively, of simulated random draws

270 from the species pool. We calculated these metrics using 10,000 random simulation. NTI is

271 similar to NRI but considers the average distance between each species and its closest relative.

272 Specifically, $X_{n e t}$ from equation 2 is replaced with $X_{\min }$ which is defined as the average distance

273 between each species and its closest relative, such that:

$$
N T I=-\frac{X_{\min }-X_{\text {null }}}{S D_{\text {null }}}
$$

276 random draws of the species pool, similar to calculations of NRI. As a consequence of

277 differences in the underlying metric of interest $\left(X_{\text {net }}\right.$ versus $\left.X_{\min }\right), N R I$ is more sensitive to

278 phylogenetic clustering deeper into the phylogeny, while NRI is more sensitive to clustering 
near the tips of the phylogeny. The significance of trends in phylogenetic structure was evaluated in two ways. First, at a community level, sites (i.e. individual communities) were considered to be significantly structured by phylogeny if NRI or NTI values ranked among the 500 most extreme values (97.5th or 2.5 th percentiles) of the 10,000 randomly generated pseudo-communities. A second approach was used to determine if, across the whole dataset,

284 there were significant trends in phylogenetic community structure. NRI and NTI are both

285 expected to be approximately normally distributed with a mean of zero, therefore in order to 286 determine whether the mean of the distribution of kelp communities differed from this null 287 expectation, t-tests were also performed, treating sites as replicates (as in Cooper et al. 2008).

Statistical software

290 All statistical analyses were performed in R version 3.6.0, using the packages "ape" (Paradis et

291 al. 2004), "phytools" (Revell 2012), "picante” (Kembel et al. 2010), "qvalue” (Bass et al. 2018),

292 “EcoSimR" (Gotelli et al. 2015), and "cooccur" (Griffith et al. 2016).

294 Results

295 Phenotypic traits are convergent across taxa

296 Principal component analysis resulted in seven component axes with the first two explaining

$29763.9 \%$ of the variation in trait values (Fig 2A). Principal component 1 (PC1) correlated with

298 structural characteristics of the whole kelp (HMF and SMF), as well as the blade (DMC, BMA),

299 which were themselves all positively correlated (Fig S1). Principal component 2 explained 
mainly the properties of materials $(\sigma, E$ and $\varepsilon$ ). These two components explained $35.3 \%$ and $=0.0136)$. There was no significant phylogenetic signal on any of the traits investigated in this

311 observation was confirmed by the lack of a significant relationship between PC1 and PC2 trait

312 distances and phylogenetic distance (PC1 Mantel test: Z-stat $=6450.835, p=0.589 ;$ PC2 Mantel

313 test: $Z$-stat $=6449.193, p=0.691)$. Ancestral state reconstruction demonstrates that trait

314 combinations have evolved repeatedly across the kelps with clear patterns of phenotypic

315 convergence (Fig S3).

317 Kelp communities are phenotypically (not phylogenetically) clustered

318 The community matrix was non-random with a c-score that exceeded the range of values from

319 random simulations (Fig S4). There were several significant associations between species (Fig

320 3). Positive and negative species associations occurred between both closely and distantly

321 related species pairs. For example, closely related species Macrocystis pyrifera and Nereocystis 
322 luetkeana were negatively associated with each other, while sister taxa, Pleurophycus gardneri

323 and Pterygophora californica, were positively associated (Fig. 3). Moreover, Egregia, the most

324 phylogenetically distinct genus from the family Arthrothamnaceae, was positively associated

325 with some members of three other families (Alariaceae, Agaraceae, Laminariaceae) and

326 negatively associated with a member of one (Agaraceae).

327

328 Despite clear evidence of non-random community assembly, there was no effect of

329 phylogenetic distance on the probability of co-occurrence between species. The only significant

330 predictor of pairwise non-random co-occurrence (measured as "co-occurrence index") was

331 distance in PC1 between species pairs (Linear regression: $F=5.075, d f=69, P=0.02746$; Fig $3 C$ ).

332 Phylogenetic distance (Linear regression: $\mathrm{F}=0.2392, \mathrm{df}=69, \mathrm{P}=0.6263$; Fig 3B) and $\mathrm{PC2}$ distances

333 (Linear regression: $F=0.3037, \mathrm{df}=69, \mathrm{P}=0.5833$; Fig 3D) did not significantly correlate with the 334 pairwise co-occurrence of species.

336 There was a significant relationship between average wave exposure of a species and its value

337 of PC1 (Linear model: $F=6.809, \mathrm{df}=1$ and $12, \mathrm{P}=0.0228 ; \mathrm{PGLS}$ model: $\mathrm{t}=3.9823, \mathrm{df}=14$ and

$3382, \mathrm{P}=0.002 ;$ Fig 4), but not PC2 (Linear model: $\mathrm{F}=0.1225, \mathrm{df}=1$ and $12, \mathrm{P}=0.732 ; \mathrm{PGLS}$ model: $\mathrm{t}$

$339=0.8316, \mathrm{df}=14$ and $2, \mathrm{P}=0.4219)$, such that structurally reinforced species tended to be

340 found at more wave exposed sites. This relationship was significant even when removing

341 Postelsia palmaeformis, the strongest and most wave tolerant species, from the analysis (Linear

342 model: $F=5.161, d f=1$ and 11, $P=0.0441 ; P G L S$ model: $t=3.0250, d f=13$ and $2, P=0.0116)$.

343 The only traits that significantly correlated with the average wave exposure of a species on their 
344 own were HMF and $\varepsilon$ (Table 2). There was a possible, but not significant negative correlation

345 between blade stiffness and average wave exposure.

347 Kelp species are phylogenetically overdispersed across local communities

348 Use of phylogenetic indices demonstrate that no communities examined were significantly

349 phylogenetically clustered and most communities trended towards phylogenetic overdispersion

350 relative to simulations (Fig 5). Although only a few sites were significantly overdispersed (NRI: $n$

$351=3, \mathrm{NTI}=7 ;$ Fig 5), average phylogenetic NRI and NTI values were significantly different from

352 zero (NRI: $t$-test: $t=3.917, d f=86, p=0.00018$; $N$ TI: $t$-test: $t=9.4708, d f=86, p<0.0001$ ). The

353 few communities that trended towards phylogenetic clustering were composed of only a small

354 number of species, where clustering of species at sites appeared to be random on average (NTI

355 and NRI approximate zero).

357 Binomial models of species presence and absence along a continuous wave exposure axis

358 further demonstrates how species in each subclade have convergently adapted to different

359 regimes of wave exposure (Fig. 6). Individual species clearly varied in distribution across the

360 gradient of wave exposure and closely related species (e.g. Nereocystis luetkeana and

361 Macrocystis pyrifera) tended to specialize in different wave exposure regimes. The clear

362 exception here is the species pair Pterygophora californica and Pleurophycus gardneri that are

363 sisters and had nearly identical distributions across the wave exposure gradient (Fig 6). There

364 was a significant effect of wave exposure category on community composition (PERMANOVA: F

$365=13.205, \mathrm{P}<0.001 ;$ Fig S5), indicating that differences in species distributions across the wave 
exposure gradient scale up to community level differences in species composition at wave exposed versus wave sheltered sites.

\section{Discussion}

370 We demonstrated evolutionary lability in the traits underlying the habitat niches of kelps and

371 suggest that this has resulted in convergent patterns of habitat use across species. Neither

372 principal component, nor any of the individual traits that make them up, were found to be

373 phylogenetically conserved across species (Table 1). In fact, for all traits, Blomberg's K was less

374 than 1, suggesting that closely related species are more dissimilar than predicted by the null

375 model (although not significant). Yet, PC1 (structural reinforcement) was a predictor of both

376 pairwise species co-occurrences (Fig 3) and the position of individual species along the gradient

377 of wave exposure (Fig 4), indicating a role of structural traits in determining the habitat niche of

378 species. We further propose that this relationship is causal on the basis that many field studies

379 and biomechanical models have demonstrated the role of rapid water motion as a strong

380 selective pressure for increased tolerance to physical forces (Johnson and Koehl 1994, Duggins

381 et al. 2003, Martone et al. 2012, Demes et al. 2013, Starko et al. 2014). 
commonly interpreted as phenotypic overdispersion and treated as evidence for competitive exclusion (e.g. Webb 2000, Webb et al. 2002, Cooper et al. 2008). The idea here being that species with similar niches will be unable to co-exist if competition is an important driver of community assembly. However, in our study, species that were commonly found together also tended to be those with correlated niches, indicative of environmental filtering, not competition. For example, Lessoniopsis littoralis and Saccharina sessilis, two distantly related

394 species that have similar values of PC1 and specialize in wave-swept environments (Fig 6), were 395 positively correlated across the community matrix (Fig 3). Conversely, species that specialize in 396 different wave exposure regimes tended to be negatively correlated. For example, Neoagarum fimbriatum, a specialist in wave sheltered areas, and Laminaria setchellii, a wave exposed specialist (Fig 6), co-occurred significantly less often than predicted (Fig 3). Thus, kelp communities are filtered strongly but the phenotypes that allow species to pass this filter have evolved convergently in different subclades, resulting in communities of species that have

401 similar phenotypes but come from different clades.

Past work has suggested that traits associated with habitat niche are highly conserved while $\alpha$

404 niche traits, which result in co-existence of taxa, are more labile (Silvertown et al. 2006a,

405 2006b; but see Cavender-Bares et al. 2004a). While this framework may hold in many groups of

406 embryophytes, we show that this is not the case for kelps. Habitat niche traits in the kelps are

407 labile and tend to be largely dissimilar among close relatives (Fig 6). While the basis of

408 convergence in traits can be challenging to interpret and may differ across taxa, we propose

409 that partitioning of habitats is an important means by which kelps achieve reproductive 
410 isolation and undergo speciation. Partitioning can occur either through character displacement,

411 where competition between close relatives drives the weaker competitor to adapt to new

412 environments (Brown and Wilson 1956), or through the splitting of a generalist niche into

413 multiple specialized niches (Funk 1998). There is substantial evidence that simultaneous

414 phenotypic and genetic divergence across the kelps is common and may be an important driver

415 of diversification. In Table 3, we describe five known instances where partitioning along a

416 gradient of wave exposure has resulted in genetic differentiation of populations or incipient

417 speciation. The prevalence of this pattern in ongoing or incipient speciation events, lends

418 support to our hypothesis that niche partitioning along a wave exposure gradients has been a

419 repeated driver of sympatric speciation and that these processes observed in past studies near

420 the tips of the phylogeny scale up to explain patterns of niche evolution across the broader kelp

421 phylogeny. Close relatives may specialize in different positions along environmental gradients,

422 leading to parallel adaptive radiation across subclades, possibly helping to maintain coexistence

423 of species across broad geographic scales (MacArthur 1958, Cavender-Bares et al. 2004b,

424 2004a, Losos 2008, Cavender-Bares et al. 2018). We further hypothesize that $\alpha$ niche traits may

425 be more conserved than $\beta$ niche traits across the kelps, leading to increased co-existence

426 between distant relatives. While it is unclear exactly what traits would promote co-existence

427 across kelp species, morphological features such as the presence of buoyant floats or long, rigid

428 stipes may be somewhat more conserved than the traits examined here, despite multiple

429 origins (Starko et al 2019b). Differences in stature within the water column have been linked to

430 competitive hierarchies in kelps (Edwards and Connell 2015) and may thus make up a

431 component of species $\alpha$ niches. 
433 Multiple hypotheses may explain why phenotypic divergence, rather than niche conservatism,

434 is the dominant process behind kelp phenotypic evolution. Kelps diversified only recently and

435 following massive changes to global climate (Starko et al. 2019b). Kelps are much larger and

436 more competitive than other macroalgal species (Edwards and Connell 2015) but rely on cool

437 waters and an abundance of nutrients. Cooling of the oceans may have created an ecological

438 opportunity for kelps, allowing them to diversify across and dominate rocky shores throughout

439 the Northeast Pacific (Bolton 2010, Starko et al. 2019b, Vermeij et al. 2019). This ecological

440 opportunity may have promoted selection for niche partitioning as has been documented

441 previously, such as in oak trees (Cavender-Bares et al. 2004a, Cavender-Bares et al. 2018), the

442 silversword alliance (Ackerly 2009, Blonder et al. 2016) and Carribean anoles (Losos et al. 2003).

443 If this is the case, then it is because of (and not in spite of) the ecological relevance of these

444 traits that we find no phylogenetic signal. This hypothesis is further supported by recent

445 evidence that temperature tolerance and chemical deterrent production, which determine the

446 geographic range limits of species and the responses of species to herbivory, respectively, are

447 also highly labile across kelps (heat tolerance: Muth et al. 2019, chemical deterrents: Starko et

448 al. 2019b). An alternative hypothesis is that these patterns are typical of marine macroalgae

449 that to date have been poorly explored in this regard. Individual macroalgae are fixed in place

450 but lineages can span broad gradients of stress and disturbance, relying only on relatively

451 simple morphological adaptations to survive. Because traits are generally simple, novelty may

452 not be particularly important in determining the habitat niche of macroalgae, and thus strong

453 selection on quantitative, heritable traits may lead to divergence being common among close 
454 relatives. This hypothesis is supported by recent work on coralline algae, showing that intense

455 grazing by urchins (analogous to environmental filtering) does not lead to phylogenetic

456 clustering (Hind et al. 2019) as predicted by assumptions of niche conservatism. Regardless of

457 the generality of our results to other marine macroalgae, we show that niche partitioning has

458 been an important driver of kelp phenotypic evolution, highlighting the importance of

459 divergent selection in the evolution of a lineage of marine foundation species. Future work

460 should investigate the extent to which these patterns extent to other marine lineages in order

461 to determine how ecological and evolutionary processes interact in the ocean.

462

\section{Conclusions}

464 We demonstrate that the distribution of phenotypic traits across the kelp phylogeny represents

465 convergent evolution of niche structure. We propose that this is a consequence of niche

466 partitioning by close relatives, with wave exposure as an important axis of niche structure.

467 More broadly, our results provide clear evidence that traits are not always phylogenetically

468 conserved and that phylogenies are not proxies for ecological differences between species, but

469 instead provide an opportunity to explore how local scale processes influence

470 macroevolutionary diversification (as argued by Gerhold et al. 2015). Phenotypic divergence

471 between close relatives may be expected in particular situations and therefore understanding

472 the circumstances and spatial scales at which phenotypic conservatism or divergence are

473 expected is the critical next step for the field of phylogenetic community ecology. 
475

476

477

478

479

480

481

482

483

484

485

486

487

488

489

490

491

492

493

494

495

496

497

498

499

500

501

502

503

\section{References}

Ackerly, D. 2009. Conservatism and diversification of plant functional traits: Evolutionary rates versus phylogenetic signal. Proceedings of the National Academy of Sciences 106:19699-19706.

Astorga, M. P., C. E. Hernández, C. P. Valenzuela, J. Avaria-Llautureo, and R. Westermeier. 2012. Origin, diversification, and historical biogeography of the giant kelps genus Macrocystis: Evidences from Bayesian phylogenetic analysis. Revista de biología marina y oceanografía 47:573-579.

Augyte, S., L. Lewis, S. Lin, C. D. Neefus, and C. Yarish. 2018. Speciation in the exposed intertidal zone: the case of Saccharina angustissima comb. nov. \& stat. nov. (Laminariales, Phaeophyceae). Phycologia 57:100-112.

Bass, J., A. Dabney, and D. Robinson. 2018. qvalue: Q-value estimation for false discovery rate control. R package version 2.14.0, http://github.com/jdstorey/qvalue.

Best, R. J., and J. J. Stachowicz. 2013. Phylogeny as a Proxy for Ecology in Seagrass Amphipods: Which Traits Are Most Conserved? PLOS ONE 8:e57550.

Blanchette, C. A., B. G. Miner, and S. D. Gaines. 2002. Geographic variability in form, size and survival of Egregia menziesii around Point Conception, California. Marine Ecology Progress Series 239:69-82.

Blomberg, S. P., T. Garland, and A. R. Ives. 2003. Testing for Phylogenetic Signal in Comparative Data: Behavioral Traits Are More Labile. Evolution 57:717-745.

Blonder, B., B. G. Baldwin, B. J. Enquist, and R. H. Robichaux. 2016. Variation and macroevolution in leaf functional traits in the Hawaiian silversword alliance (Asteraceae). Journal of Ecology 104:219-228.

Bolton, J. J. 2010. The biogeography of kelps (Laminariales, Phaeophyceae): a global analysis with new insights from recent advances in molecular phylogenetics. Helgoland Marine Research 64:263-279.

Brown, W. L., and E. O. Wilson. 1956. Character Displacement. Systematic Zoology 5:49-64.

Burel, T., G. Schaal, J. Grall, M. Le Duff, G. Chapalain, B. Schmitt, M. Gemin, O. Boucher, and E. Ar Gall. 2019. Small-scale effects of hydrodynamics on the structure of intertidal 
macroalgal communities: A novel approach. Estuarine, Coastal and Shelf Science 226:106290.

506

507

\section{8}

509

Buzas, M. A., and S. J. Culver. 1991. Species Diversity and Dispersal of Benthic Foraminifera. BioScience 41:483-489.

Camus, C., S. Faugeron, and A. H. Buschmann. 2018. Assessment of genetic and phenotypic diversity of the giant kelp, Macrocystis pyrifera, to support breeding programs. Algal Research 30:101-112.

Cavalheri, H., C. Both, and M. Martins. 2015. The Interplay between Environmental Filtering and Spatial Processes in Structuring Communities: The Case of Neotropical Snake Communities. PLOS ONE 10:e0127959.

Cavender-Bares, J., D. D. Ackerly, D. A. Baum, and F. A. Bazzaz. 2004a. Phylogenetic overdispersion in Floridian oak communities. The American Naturalist 163:823-843.

Cavender-Bares, J., K. Kitajima, and F. A. Bazzaz. 2004b. Multiple Trait Associations in Relation to Habitat Differentiation Among 17 Floridian Oak Species. Ecological Monographs 74:635-662.

Cavender-Bares, J., S. Kothari, J. E. Meireles, M. A. Kaproth, P. S. Manos, and A. L. Hipp. 2018. The role of diversification in community assembly of the oaks (Quercus L.) across the continental U.S. American Journal of Botany 105:565-586.

Cavender-Bares, J., K. H. Kozak, P. V. A. Fine, and S. W. Kembel. 2009. The merging of community ecology and phylogenetic biology. Ecology Letters 12:693-715.

Cooper, N., J. Rodríguez, and A. Purvis. 2008. A common tendency for phylogenetic overdispersion in mammalian assemblages. Proceedings of the Royal Society of London B: Biological Sciences 275:2031-2037.

Cornwell, W. K., and D. D. Ackerly. 2009. Community assembly and shifts in plant trait distributions across an environmental gradient in coastal California. Ecological Monographs 79:109-126.

Coyer, L. M., and J. A. Roberson. 2004. Variation in blade morphology of the kelp Eisenia arborea: incipient speciation due to local water motion? Marine Ecology Progress Series 282:115-128. 
533 Darwin, C. 1859. On the origin of species by means of natural selection. Murray, London 502.

534 Demes, K. W., J. N. Pruitt, C. D. G. Harley, and E. Carrington. 2013. Survival of the weakest:

535 increased frond mechanical strength in a wave-swept kelp inhibits self-pruning and

536 increases whole-plant mortality. Functional Ecology 27:439-445.

537 Denny, M., and B. Gaylord. 2002. The mechanics of wave-swept algae. Journal of Experimental 538 Biology 205:1355-1362.

539 Denny, M. W. 1985. Wave forces on intertidal organisms: A case study1. Limnology and $540 \quad$ Oceanography 30:1171-1187.

541 Druehl, L. D., and C. T. J. Elliot. 1996. Parks Canada Barkley Sound Kelp Distribution. Parks $542 \quad$ Canada Contract \#K3489-3-0006.

543 Duggins, D. O., J. E. Eckman, C. E. Siddon, and T. Klinger. 2003. Population, morphometric and 544 biomechanical studies of three understory kelps along a hydrodynamic gradient. Marine $545 \quad$ Ecology Progress Series 265:57-76.

546 Edwards, M. S., and S. D. Connell. 2015. Chapter 7 Competition, a Major Factor Structuring $547 \quad$ Seaweed Communities.

548 Elliot, M. G., and A. Ф. Mooers. 2014. Inferring ancestral states without assuming neutrality or gradualism using a stable model of continuous character evolution. BMC Evolutionary

551 Emerson, B. C., and R. G. Gillespie. 2008. Phylogenetic analysis of community assembly and 552 structure over space and time. Trends in Ecology \& Evolution 23:619-630.

553 Enquist, B. J., J. Norberg, S. P. Bonser, C. Violle, C. T. Webb, A. Henderson, L. L. Sloat, and V. M. 554 Savage. 2015. Scaling from traits to ecosystems: Developing a general Trait Driver Theory via integrating trait-based and metabolic scaling theories. arXiv:1502.06629 [q-

557 Funk, D. J. 1998. Isolating a role for natural selection in speciation: host adaptation and sexual isolation in Neochlamisus bebbianae leaf beetles. Evolution; International Journal of

560 Gaylord, B., C. A. Blanchette, and M. W. Denny. 1994. Mechanical Consequences of Size in Wave-Swept Algae. Ecological Monographs 64:287-313. 
Gerhold, P., J. F. Cahill, M. Winter, I. V. Bartish, and A. Prinzing. 2015. Phylogenetic patterns are not proxies of community assembly mechanisms (they are far better). Functional Ecology 29:600-614.

Gotelli, N. J., E. M. Hart, and A. M. Ellison. 2015. EcoSimR: Null model analysis for ecological data. Zenodo.

Graham, M. H. 2004. Effects of Local Deforestation on the Diversity and Structure of Southern California Giant Kelp Forest Food Webs. Ecosystems 7:341-357.

Griffith, D. M., J. A. Veech, and C. J. Marsh. 2016. cooccur: Probabilistic Species Co-Occurrence Analysis in R. Journal of Statistical Software 69:1-17.

Harley, C. D. G., and B. S. T. Helmuth. 2003. Local- and regional-scale effects of wave exposure, thermal stress, and absolute versus effective shore level on patterns of intertidal zonation. Limnology and Oceanography 48:1498-1508.

Hector, A., and R. Hooper. 2002. Ecology. Darwin and the first ecological experiment. Science (New York, N.Y.) 295:639-640.

Henkel, S. K., G. E. Hofmann, and A. C. Whitmer. 2007. Morphological and genetic variation in Egregia menziesii over a latitudinal gradient. Botanica Marina 50:159-170.

Hind, K. R., S. Starko, J. M. Burt, M. A. Lemay, A. K. Salomon, and P. T. Martone. 2019. Trophic control of cryptic coralline algal diversity. Proceedings of the National Academy of Sciences 116:15080-15085.

Hurd, C. L. 2017. Shaken and stirred: the fundamental role of water motion in resource acquisition and seaweed productivity. Perspectives in Phycology 4:73-81.

Jackson, C., E. D. Salomaki, C. E. Lane, and G. W. Saunders. 2017. Kelp transcriptomes provide robust support for interfamilial relationships and revision of the little known Arthrothamnaceae (Laminariales). Journal of Phycology 53:1-6.

Johnson, A., and M. Koehl. 1994. Maintenance of dynamic strain similarity and environmental stress factor in different flow habitats: thallus allometry and material properties of a giant kelp. The Journal of Experimental Biology 195:381-410.

Kawai, H., T. Hanyuda, L. M. Ridgway, and K. Holser. 2013. Ancestral reproductive structure in basal kelp Aureophycus aleuticus. Scientific Reports 3:1-7. 
Kembel, S. W., P. D. Cowan, M. R. Helmus, W. K. Cornwell, H. Morlon, D. D. Ackerly, S. P. Blomberg, and C. O. Webb. 2010. Picante: R tools for integrating phylogenies and ecology. Bioinformatics (Oxford, England) 26:1463-1464.

Kopczak, C. D., R. C. Zimmerman, and J. N. Kremer. 1991. Variation in Nitrogen Physiology and Growth Among Geographically Isolated Populations of the Giant Kelp, Macrocystis Pyrifera (phaeophyta)1. Journal of Phycology 27:149-158.

Kraft, N. J. B., P. B. Adler, O. Godoy, E. C. James, S. Fuller, and J. M. Levine. 2014. Community assembly, coexistence and the environmental filtering metaphor. Functional Ecology 29:592-599.

Kraft, N. J. B., W. K. Cornwell, C. O. Webb, and D. D. Ackerly. 2007. Trait Evolution, Community Assembly, and the Phylogenetic Structure of Ecological Communities. The American Naturalist 170:271-283.

Kraft, N. J., L. S. Comita, J. M. Chase, N. J. Sanders, N. G. Swenson, T. O. Crist, J. C. Stegen, M. Vellend, B. Boyle, and M. J. Anderson. 2011. Disentangling the drivers of $\beta$ diversity

Littler, M. M., and D. S. Littler. 1984. Relationships between macroalgal functional form groups and substrata stability in a subtropical rocky-intertidal system. Journal of Experimental Marine Biology and Ecology 74:13-34.

Lopez, B., K. Burgio, M. Carlucci, K. Palmquist, A. Parada, V. Weinberger, and A. Hurlbert. 2016. A new framework for inferring community assembly processes using phylogenetic information, relevant traits and environmental gradients. One Ecosystem 1:e9501. between phylogenetic relatedness and ecological similarity among species. Ecology Letters 11:995-1003. 
618

619

620

621

622

623

624

625

626

627

628

629

630

631

632

633

634

635

636

637

638

639

640

641

642

643

644

645

646

Losos, J. B., M. Leal, R. E. Glor, K. de Queiroz, P. E. Hertz, L. Rodríguez Schettino, A. Chamizo Lara, T. R. Jackman, and A. Larson. 2003. Niche lability in the evolution of a Caribbean lizard community. Nature 424:542-545.

MacArthur, R. H. 1958. Population Ecology of Some Warblers of Northeastern Coniferous Forests. Ecology 39:599-619.

Martone, P. T. 2006. Size, strength and allometry of joints in the articulated coralline Calliarthron. Journal of Experimental Biology 209:1678-1689.

Martone, P. T. 2007. Kelp versus coralline: cellular basis for mechanical strength in the waveswept seaweed Calliarthron (Corallinaceae, Rhodophyta). Journal of Phycology 43:882891.

Martone, P. T., L. Kost, and M. Boller. 2012. Drag reduction in wave-swept macroalgae: alternative strategies and new predictions. American Journal of Botany 99:806-815.

Menge, B. A., and J. P. Sutherland. 1987. Community Regulation: Variation in Disturbance, Competition, and Predation in Relation to Environmental Stress and Recruitment. The American Naturalist 130:730-757.

Miller, K. A., J. L. Olsen, and W. T. Stam. 2000. Genetic divergence correlates with morphological and ecological subdivision in the deep-water elk kelp, Pelagophycus porra (Phaeophyceae). Journal of Phycology 36:862-870.

Muth, A. F., M. H. Graham, C. E. Lane, and C. D. G. Harley. 2019. Recruitment tolerance to increased temperature present across multiple kelp clades. Ecology 100:e02594.

Neufeld, C. J., S. Starko, and K. Burns. 2017. Disturbance and diversity in a continental archipelago: A mechanistic framework linking area, height, and exposure. Ecosphere 8:e01957.

Nielsen, K. J., C. A. Blanchette, B. A. Menge, and J. Lubchenco. 2006. Physiological snapshots reflect ecological performance of the sea palm, Postelsia palmaeformis (Phaeophycaea) across intertidal elevation and exposure gradients. Journal of Phycology 42:548-559.

Pagel, M. 1999. Inferring the historical patterns of biological evolution. Nature 401:877-884. Paradis, E., J. Claude, and K. Strimmer. 2004. APE: Analyses of Phylogenetics and Evolution in R language. Bioinformatics 20:289-290. 
647

648

649

650

651

652

653

654

655

656

657

658

659

660

661

662

663

664

665

666

667

668

669

670

671

672

673

674

Reich, P. B., and J. Oleksyn. 2004. Global patterns of plant leaf $\mathrm{N}$ and $\mathrm{P}$ in relation to temperature and latitude. Proceedings of the National Academy of Sciences 101:1100111006.

Revell, L. J. 2012. phytools: an R package for phylogenetic comparative biology (and other things). Methods in Ecology and Evolution 3:217-223.

Rothman, M. Lydiane, R. J. Anderson, J. J. Bolton, and H. Verbruggen. 2017. A phylogeographic investigation of the kelp genus Laminaria (Laminariales, Phaeophyceae), with emphasis on the South Atlantic Ocean. Journal of Phycology 53:778-789.

Schluter, D. 2000. The Ecology of Adaptive Radiation. OUP Oxford.

Silvertown, J., M. Dodd, D. Gowing, C. Lawson, and K. McConway. 2006a. Phylogeny and the Hierarchical Organization of Plant Diversity. Ecology 87:S39-S49.

Silvertown, J., K. McConway, D. Gowing, M. Dodd, M. F. Fay, J. A. Joseph, and K. Dolphin. $2006 b$. Absence of phylogenetic signal in the niche structure of meadow plant communities. Proceedings of the Royal Society B: Biological Sciences 273:39-44.

Starko, S., L. A. Bailey, E. Creviston, K. A. James, A. Warren, M. K. Brophy, A. Danasel, M. P. Fass, J. A. Townsend, and C. J. Neufeld. 2019a. Environmental heterogeneity mediates scaledependent declines in kelp diversity on intertidal rocky shores. PLOS ONE 14:e0213191.

Starko, S., and P. Martone. 2016. Evidence of an evolutionary-developmental trade-off between drag avoidance and tolerance strategies in wave-swept intertidal kelps (Laminariales, Phaeophyceae). Journal of Phycology 52: 54-63..

Starko, S., M. Soto Gomez, H. Darby, K. W. Demes, H. Kawai, N. Yotsukura, S. C. Lindstrom, P. J. Keeling, S. W. Graham, and P. T. Martone. 2019b. A comprehensive kelp phylogeny sheds light on the evolution of an ecosystem. Molecular Phylogenetics and Evolution 136:138-150.

Starko, S., B. Z Claman, and P. Martone. 2014. Biomechanical consequences of branching in flexible wave-swept macroalgae New Phytologist 206: 133-140.

Steneck, R. S., and M. N. Dethier. 1994. A functional group approach to the structure of algaldominated communities. 
675

676

677

678

679

680

681

682

683

684

685

686

687

688

689

690

691

692

693

694

695

696

697

698

699

700

701

702

703

Steneck, R. S., M. H. Graham, B. J. Bourque, D. Corbett, J. M. Erlandson, J. A. Estes, and M. J. Tegner. 2002. Kelp forest ecosystems: biodiversity, stability, resilience and future. Environmental Conservation 29:436-459.

Stone, L., and A. Roberts. 1990. The checkerboard score and species distributions. Oecologia 85:74-79.

Swenson, N. G., and B. J. Enquist. 2007. Ecological and evolutionary determinants of a key plant functional trait: wood density and its community-wide variation across latitude and elevation. American Journal of Botany 94:451-459.

Teagle, H., S. J. Hawkins, P. J. Moore, and D. A. Smale. 2017. The role of kelp species as biogenic habitat formers in coastal marine ecosystems. Journal of Experimental Marine Biology and Ecology 492:81-98.

Ulrich, W., P. Sewerniak, R. Puchałka, and M. Piwczyński. 2017. Environmental filtering triggers community assembly of forest understorey plants in Central European pine stands. Scientific Reports 7:274.

van der Valk, A. G. 1981. Succession in Wetlands: A Gleasonian Approach. Ecology 62:688-696.

Vamosi, S. M., S. B. Heard, J. C. Vamosi, and C. O. Webb. 2009. Emerging patterns in the comparative analysis of phylogenetic community structure. Molecular Ecology 18:572592.

Verbruggen, H., L. Tyberghein, K. Pauly, C. Vlaeminck, K. V. Nieuwenhuyze, W. H. C. F. Kooistra, F. Leliaert, and O. D. Clerck. 2009. Macroecology meets macroevolution: evolutionary niche dynamics in the seaweed Halimeda. Global Ecology and Biogeography 18:393405.

Vermeij, G. J., R. Banker, L. R. Capece, E. S. Hernandez, S. O. Salley, V. P. Vriesman, and B. E. Wortham. 2019. The coastal North Pacific: Origins and history of a dominant marine biota. Journal of Biogeography 46:1-18.

Webb, C. O. 2000. Exploring the Phylogenetic Structure of Ecological Communities: An Example for Rain Forest Trees. The American Naturalist 156:145-155.

Webb, C. O., D. D. Ackerly, M. A. McPeek, and M. J. Donoghue. 2002. Phylogenies and Community Ecology. Annual Review of Ecology and Systematics 33:475-505. 
704 Wernberg, T., K. Krumhansl, K. Filbee-Dexter, and M. F. Pedersen. 2019. Chapter 3 - Status and

705 Trends for the World's Kelp Forests. Pages 57-78 in C. Sheppard, editor. World Seas: an

706 Environmental Evaluation (Second Edition). Academic Press.

707 Wiens, J. J. 2008. Commentary on Losos (2008): niche conservatism déjà vu. Ecology Letters 708 11:1004-1005. 


\section{Tables and Figures}

Table 1. Statistical testing of phylogenetic signal for quantitative traits

\begin{tabular}{lllll}
\hline \multicolumn{5}{l}{ Phylogenetic Signal } \\
& Blomberg's K & P-value & Pagel's Lambda & P-value \\
\cline { 2 - 4 } PC1 & 0.538 & 0.610 & $<0.01$ & $>0.99$ \\
PC2 & 0.612 & 0.425 & $<0.01$ & $>0.99$ \\
HMF & 0.353 & 0.693 & $<0.01$ & $>0.99$ \\
SMF & 0.860 & $0.063^{*}$ & 1.128 & $0.085^{*}$ \\
BMA & 0.718 & 0.190 & $<0.01$ & $>0.99$ \\
DMC & 0.521 & 0.649 & $<0.01$ & $>0.99$ \\
Strength & 0.584 & 0.457 & 0.108 & 0.737 \\
Stiffness & 0.720 & 0.197 & 0.303 & 0.437 \\
Extensibility & 0.285 & 0.962 & $<0.01$ & $>0.99$ \\
\hline
\end{tabular}

${ }^{*}$ Trending towards significance $(\mathrm{P}<0.10)$ 
Table 2. Results of PGLS models testing for correlations between traits and average wave exposure of species $(\mathrm{df}=1,12)$

\begin{tabular}{lll}
\hline Functional Traits & t-statistic & P-value \\
\hline PC1 & 3.9283 & $0.0020^{*}$ \\
PC2 & 0.8316 & 0.4219 \\
HMF & 3.8602 & $0.0023^{* *}$ \\
SMF & 0.9203 & 0.3756 \\
BMA & 1.0040 & 0.3351 \\
DMC & 1.5138 & 0.1560 \\
Strength & 0.8776 & 0.3974 \\
Stiffness & -2.1020 & $0.0573^{*}$ \\
Extensibility & 2.2003 & $0.0481^{* *}$ \\
\hline
\end{tabular}

*Trending towards significance $(\mathrm{P}<0.10)$

$* *$ Significant relationship $(\mathrm{P}<0.05)$ 
Table 3. Evidence of incipient speciation occurring across gradients of wave exposure

\begin{tabular}{|c|c|c|c|c|}
\hline Species & $\begin{array}{l}\text { Environmental } \\
\text { gradient }\end{array}$ & Description & Evidence of differentiation & References \\
\hline Ecklonia arborea & Wave exposure & $\begin{array}{l}\text { Genetic differentiation } \\
\text { associated with changes in } \\
\text { blade morphology and wave } \\
\text { exposure }\end{array}$ & M13 DNA Fingerprinting & $\begin{array}{l}\text { Roberson \& Coyer } \\
2004\end{array}$ \\
\hline $\begin{array}{l}\text { Egregia } \\
\text { menziesii }\end{array}$ & $\begin{array}{l}\text { Wave exposure, } \\
\text { latitude }\end{array}$ & $\begin{array}{l}\text { Difference in blade and rachus } \\
\text { morphology at wave exposed } \\
\text { versus sheltered sites; evidence } \\
\text { of differential mortality } \\
\text { depending on morphology }\end{array}$ & $\begin{array}{l}\text { No direct evidence of genetic } \\
\text { differentiation with ITS, despite } \\
\text { parapatric overlap of } \\
\text { populations. Reciprocal } \\
\text { transplants suggest phenotype is } \\
\text { genetically determined }\end{array}$ & $\begin{array}{l}\text { Blanchette et al. } \\
2002 \text {, Henkel et } \\
\text { al. } 2007\end{array}$ \\
\hline $\begin{array}{l}\text { Macrocystis } \\
\text { pyrifera }\end{array}$ & $\begin{array}{l}\text { Wave exposure, outer } \\
\text { versus inner coast }\end{array}$ & $\begin{array}{l}\text { Difference between wave } \\
\text { exposed and wave sheltered } \\
\text { morphs; phenotypic-genetic } \\
\text { correlations among juveniles } \\
\text { suggest local adaptation and } \\
\text { differentiation }\end{array}$ & $\begin{array}{l}\text { Genetic distance in ITS2 and } \\
\text { microsatellites; Spatially isolated } \\
\text { (outer coast vs. Sea of Chiloe) }\end{array}$ & $\begin{array}{l}\text { Kopczak et al. } \\
\text { 1991, Astorga et } \\
\text { al. 2012, Camus } \\
\text { et al. } 2018\end{array}$ \\
\hline $\begin{array}{l}\text { Pelagophycus } \\
\text { porra }\end{array}$ & $\begin{array}{l}\text { Wave exposure, } \\
\text { substrate }\end{array}$ & $\begin{array}{l}\text { Two distinct morphologies } \\
\text { known from the Channel } \\
\text { Islands, one on wave exposed } \\
\text { sides of islands, the other from } \\
\text { wave protected sides. Exposed } \\
\text { sites are rocky, sheltered sites } \\
\text { are mixed with soft sediment }\end{array}$ & $\begin{array}{l}\text { Random amplified polymorphic } \\
\text { DNA show isolation, ITS shows } \\
\text { no differentiation }\end{array}$ & Miller et al. 2000 \\
\hline $\begin{array}{l}\text { Saccharina } \\
\text { latissima sensu } \\
\text { lato }\end{array}$ & Wave exposure & $\begin{array}{l}\text { A wave-exposed specialist } \\
\text { population from Maine was } \\
\text { described as new species, } \\
\text { Saccharina angustissima, } \\
\text { making S. latissima } \\
\text { paraphyletic }\end{array}$ & $\begin{array}{l}\text { Difference in rbcL and cox3 (but } \\
\text { not cox1) between } S \text {. } \\
\text { angustissima and S. latissima } \\
\text { populations from Maine; } \\
\text { common garden revealed that } \\
\text { blade shape is genetically } \\
\text { determined }\end{array}$ & Augyte et al. 2018 \\
\hline
\end{tabular}


A

Environmental Gradient

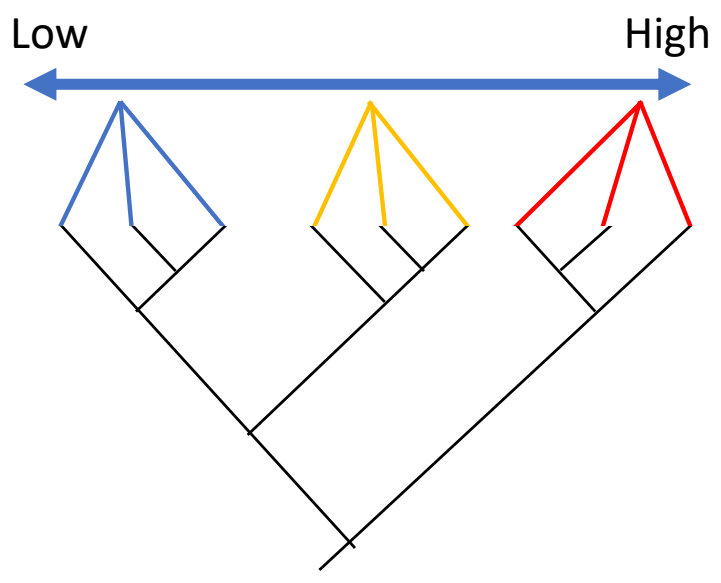

Niche conservatism
B

\section{Environmental Gradient}

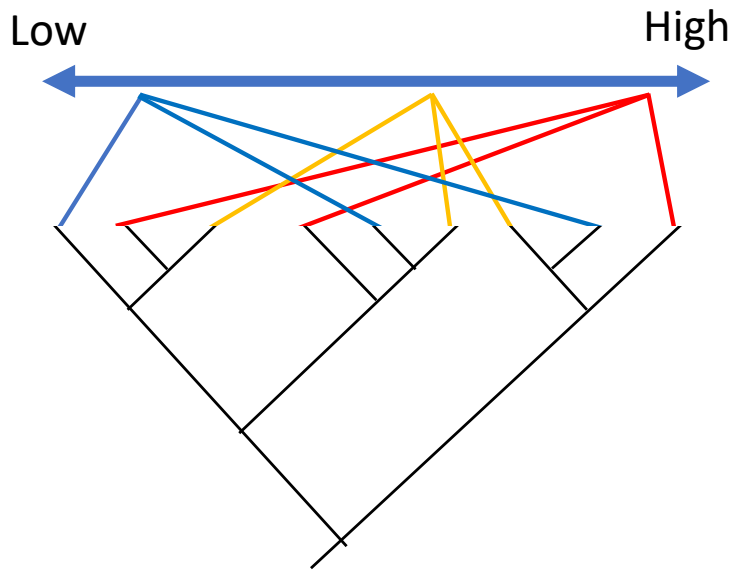

Niche partitioning

Fig 1. Theoretical extremes of how communities might be phylogenetically structured along environmental gradients under different dominant evolutionary processes. Lines are drawn from tips of the phylogeny to one of three communities situated along a theoretical disturbance gradient. Colours indicate a particular set of traits and environmental filtering drives trait clustering in both examples. If niches are conserved within subclades, then communities are expected to be clustered phylogenetically (Panel A; e.g., Webb 2000). If close relatives partition niches across the environmental gradient, then communities are expected to be phylogenetically overdispersed (Panel B; e.g., Cavender-Bares et al. 2004a). 


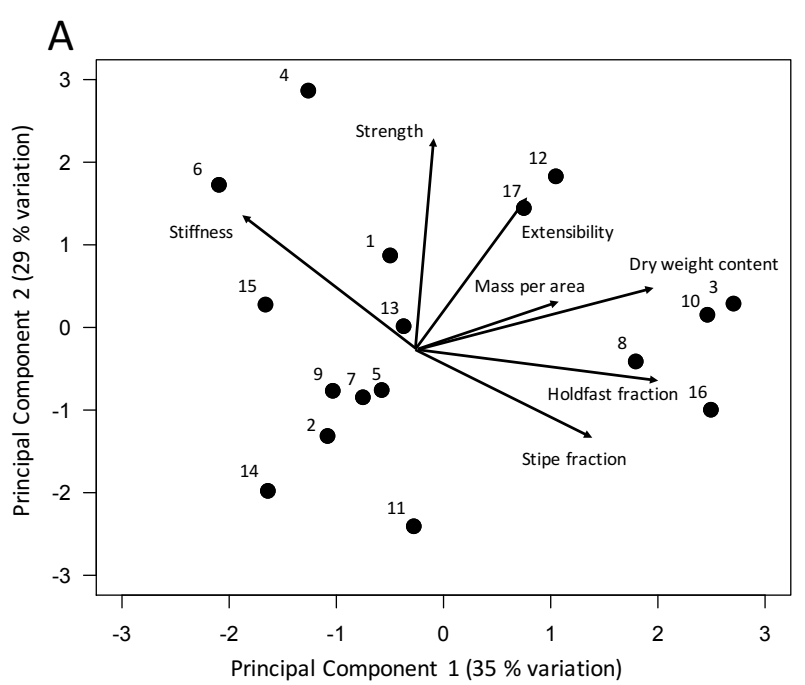

\section{B}

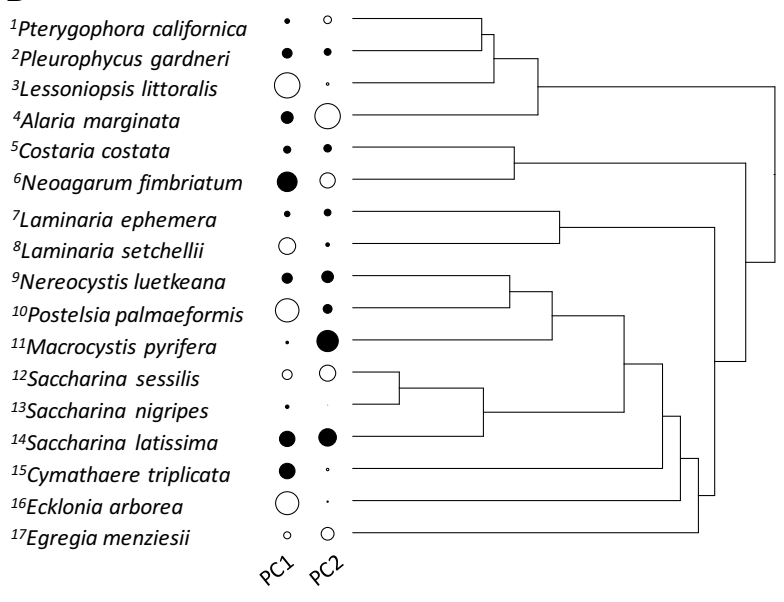

Fig 2. Phylogenetic distribution of trait axes in northeast Pacific kelp species. Panel A shows the first two principal component axes. Panel B shows PC1 and PC2 plotted on the phylogeny. The size of each bubble indicates the value of each trait axis and the colour indicates whether values are positive (white) or negative (black). There is no significant phylogenentic signal in either axis. 

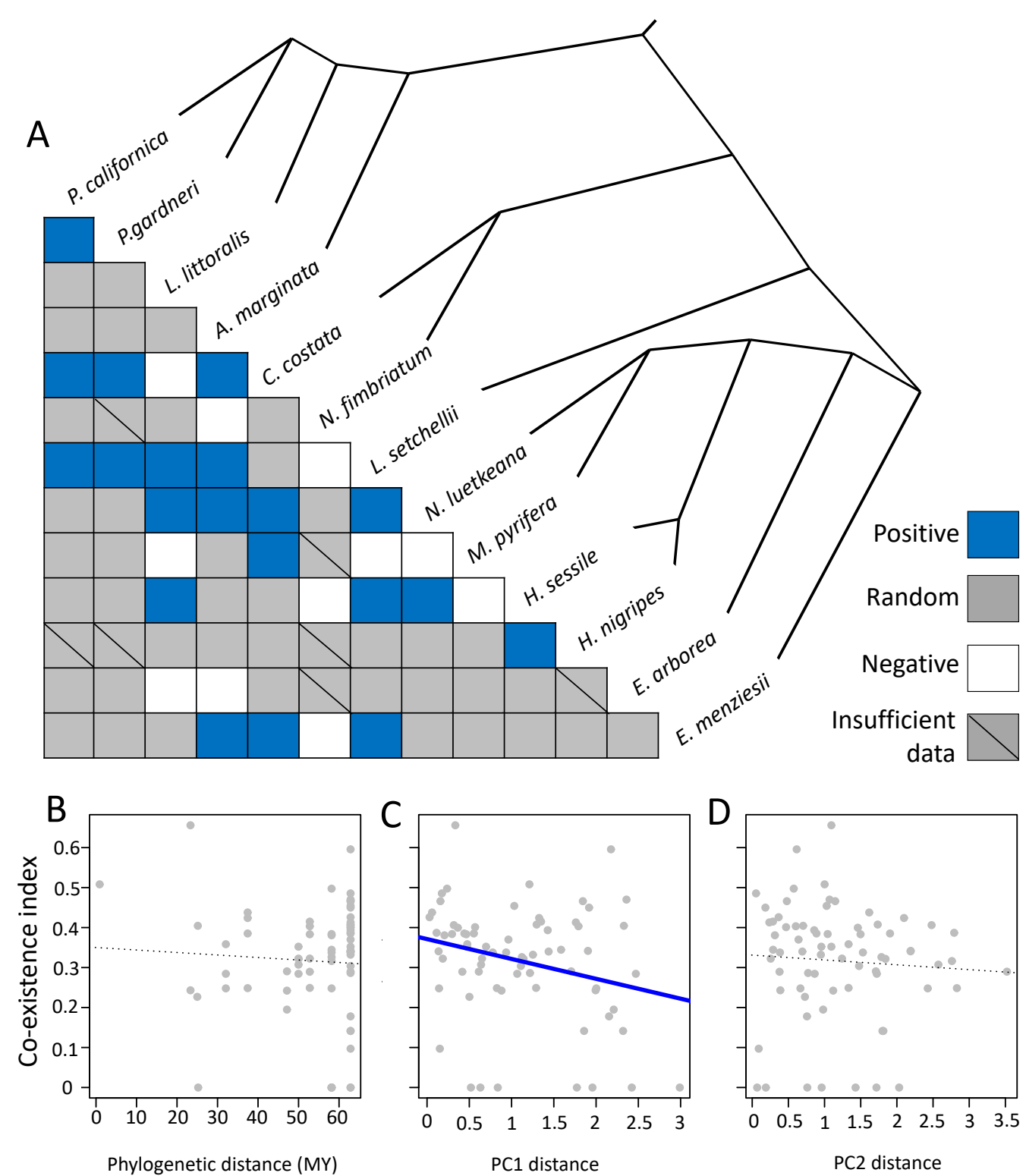

Fig 3. (A) Correlation matrix of species pairs. Colour in each cell indicates whether there was a significant positive or negative correlation between the occurrences of each pair of species, after correcting for false detection rate $(\mathrm{q}<0.05)$. (B-D) Co-occurrence index [ $\log (($ observed cooccurrence / expected co-occurrence) +1$)$ ] versus (A) phylogenetic distance between species pairs in millions of years, (B) distance in PC1 for each species pair and, (C) distance in PC2 for each species pair. Dotted lines indicate insignificant trends, while the solid blue line in panel B indicates a significant slope $(\mathrm{P}<0.05)$. 


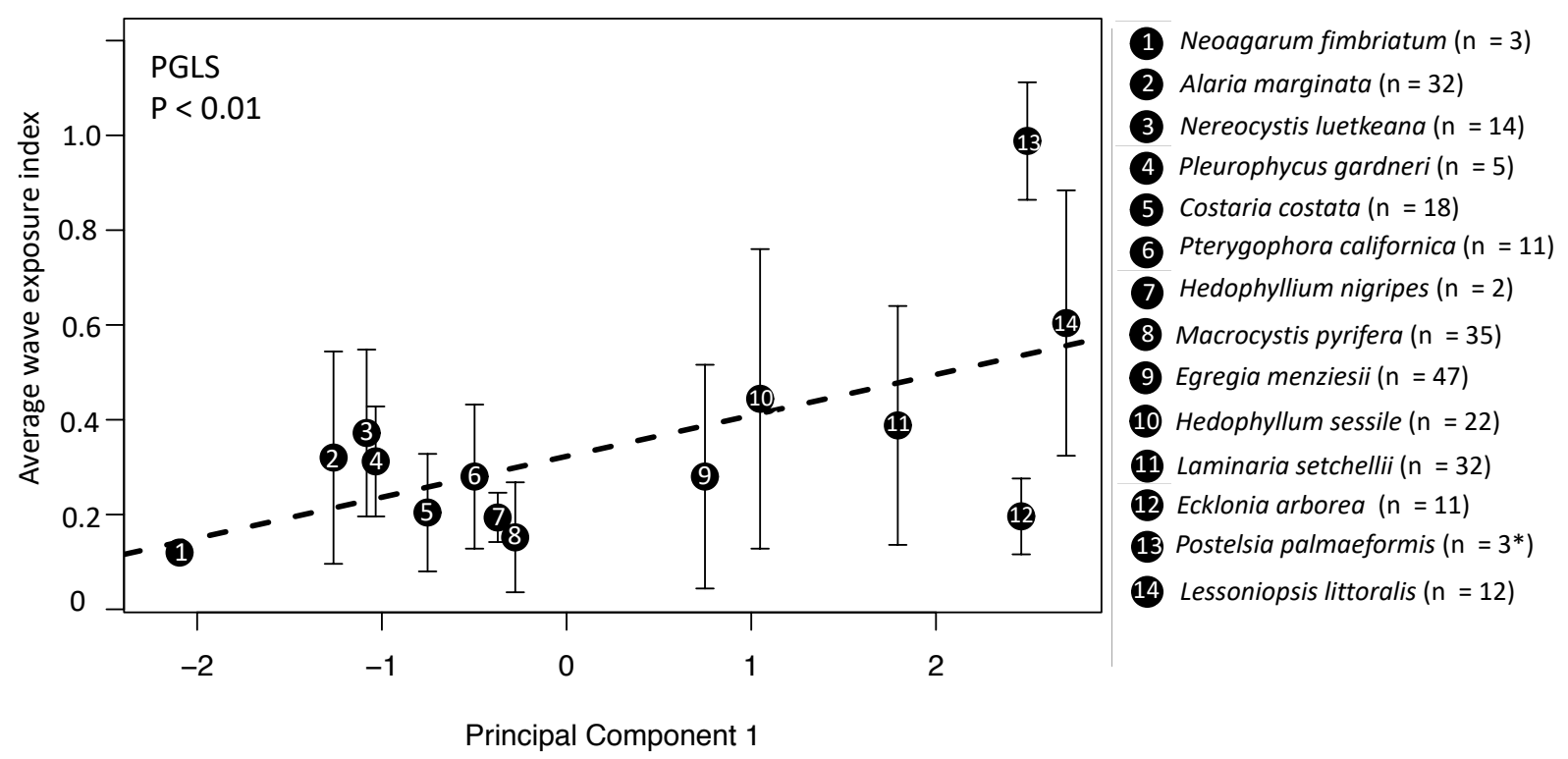

Fig 4. Relationship between wave exposure and principal component 1 . Data points represent the average wave exposure that a species was found at (+/- variance) plotted against its value of PC1. 

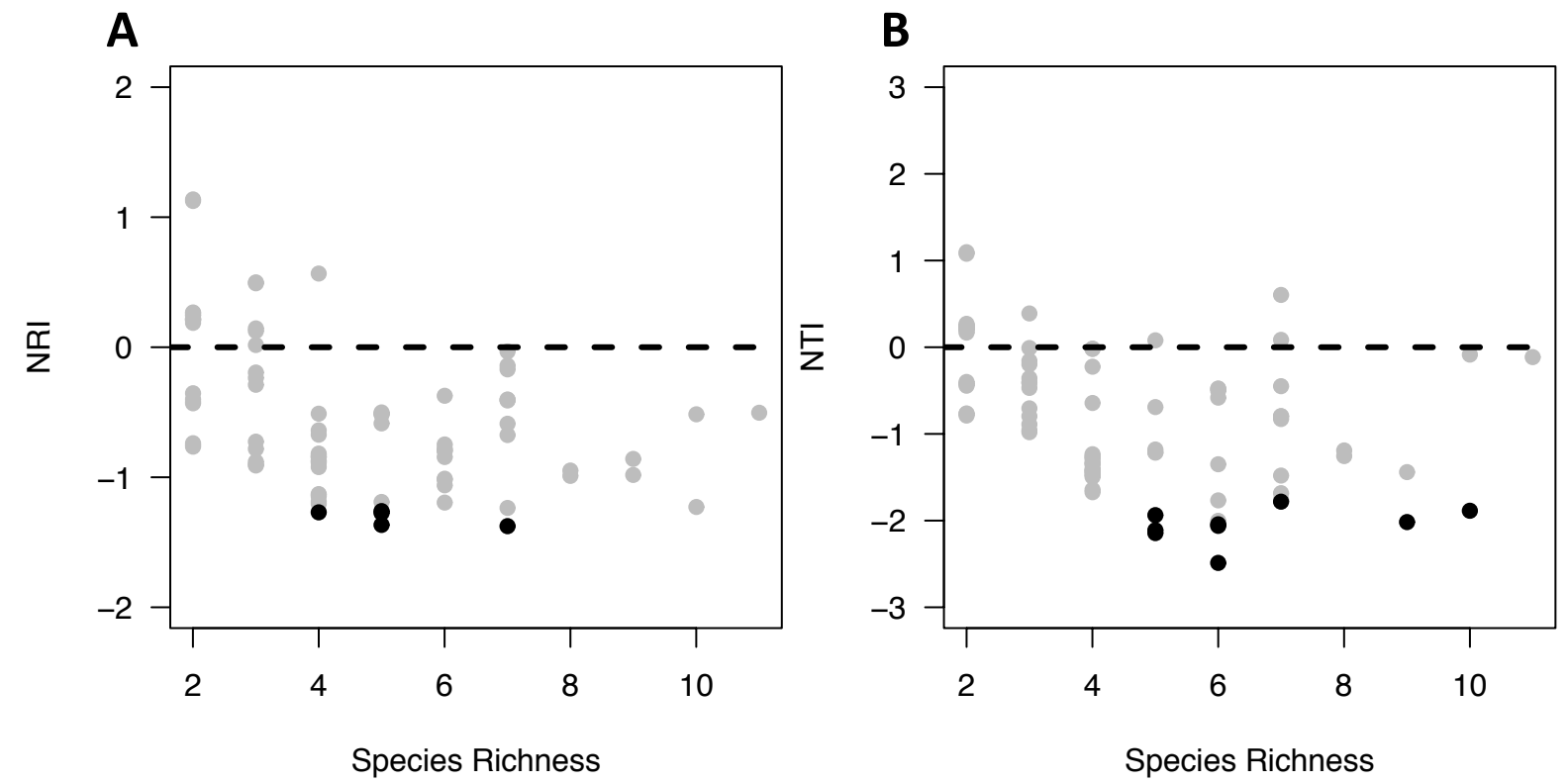

Fig 5. Metrics of phylogenetic community assembly (NRI and NTI) plotted against the species richness of communities. Data points represent individual communities and significance is indicated with dot colour. Black dots indicate that communities are significantly structured by phylogeny, while grey dots indicate no significant phylogenetic effect. 


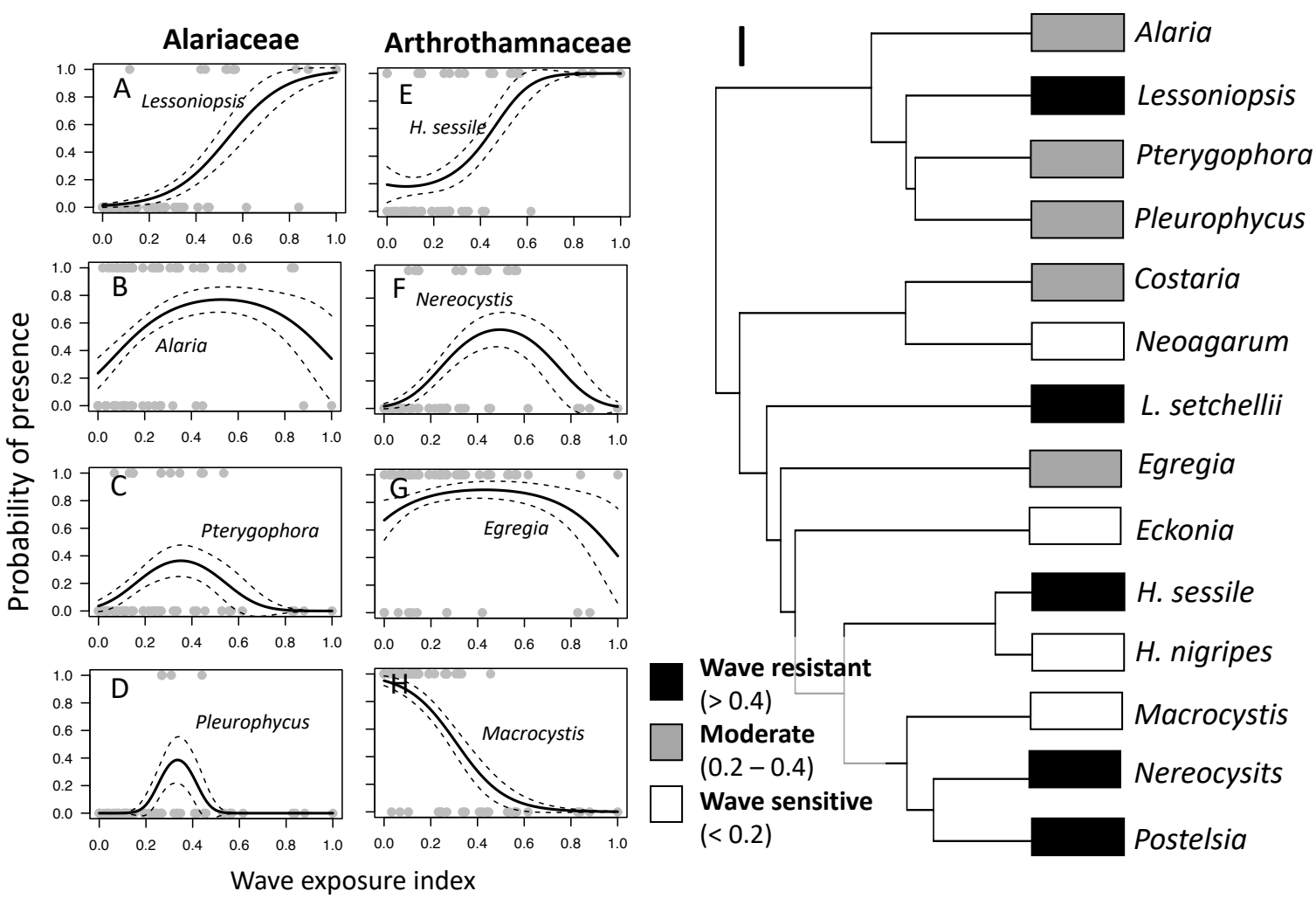

Fig 6. (A-H) Logistic polynomial regressions of species occupancy across a gradient of wave exposure. Columns represent members of two different kelp families (left $=$ Alariaceae, right $=$ Arthrothamnaceae). (I) Phylogeny of the kelps with average wave exposure split into three categories: wave resistant species, moderate species and wave sensitive species. 


\section{Supplemental Information for "Convergent evolution of niche structure in Northeast Pacific kelp forests"}

Table S1. Locations of field sites from which trait data were collected on different species

\begin{tabular}{llll}
\hline Site Name & Location & Latitude & Longitude \\
\hline Bamfield Inlet & Barkley Sound, BC & 48.8345 & -125.13682 \\
Brady's Blowhole & Barkley Sound, BC & 48.82329 & -125.16151 \\
Edward King Island & Barkley Sound, BC & 48.82235 & -125.21731 \\
Scott's Bay & Barkley Sound, BC & 48.83413 & -125.14775 \\
Prasiola Point & Barkley Sound, BC & 48.81751 & -125.16926 \\
Cape Beale & Barkley Sound, BC & 48.78537 & -125.2165 \\
Ogden Point & Victoria, BC & 48.41399 & -123.38572 \\
Botanical Beach & Port Renfrew, BC & 48.52753 & -124.44877 \\
Whytecliff Park & Vancouver, BC & 49.37226 & -123.29212 \\
\hline
\end{tabular}


Table S2. Sources of trait data used in this study. $\sigma=$ breaking stress, $E=$ tensile modulus (stiffness), $\varepsilon=$ extensibility, $\mathrm{SMF}=$ stipe mass fraction, $\mathrm{HMF}=$ holdfast mass fraction, $\mathrm{DMC}=$ dry matter content of blades, BMA = blade mass per area.

\begin{tabular}{|c|c|c|c|}
\hline Species & Materials $(\sigma, E \& \varepsilon)$ & Biomass (SMF \& HMF) & $\begin{array}{l}\text { Blade Properties (DMC \& } \\
\text { LMA) }\end{array}$ \\
\hline Alaria marginata & $\begin{array}{l}\text { This study, Botanical } \\
\text { Beach }(n=8)\end{array}$ & $\begin{array}{l}\text { Starko \& Martone } 2016 \\
(n=5)\end{array}$ & $\begin{array}{l}\text { This study, Blowhole } \\
(n=10)\end{array}$ \\
\hline Lessoniopsis littoralis & $\begin{array}{l}\text { This study, Brady's } \\
\text { Blowhole }(n=5)\end{array}$ & $\begin{array}{l}\text { Starko \& Martone } 2016 \\
(n=5)\end{array}$ & $\begin{array}{l}\text { This study, Blowhole } \\
(n=9)\end{array}$ \\
\hline Pleurophycus gardneri & $\begin{array}{l}\text { This study, Ogden } \\
\text { Point }(n=5)\end{array}$ & $\begin{array}{l}\text { Starko \& Martone } 2016 \\
(n=5)\end{array}$ & $\begin{array}{l}\text { This study, Ogden Point } \\
(n=6)\end{array}$ \\
\hline Pterygophora californica & $\begin{array}{l}\text { This study, Botanical } \\
\text { Beach }(n=8)\end{array}$ & $\begin{array}{l}\text { Starko \& Martone } 2016 \\
(n=5)\end{array}$ & $\begin{array}{l}\text { This study, Ogden Point } \\
(n=2)\end{array}$ \\
\hline Costaria costata & $\begin{array}{l}\text { This study, Whytecliff } \\
\text { Park } \\
(n=8)\end{array}$ & $\begin{array}{l}\text { Starko \& Martone } 2016 \\
(n=5)\end{array}$ & $\begin{array}{l}\text { This study, Scott's Bay } \\
(n=3)\end{array}$ \\
\hline Neoagarum fimbriatum & $\begin{array}{l}\text { This study, Whytecliff } \\
\text { Park } \\
(n=8)\end{array}$ & $\begin{array}{l}\text { Starko \& Martone } 2016 \\
(n=5)\end{array}$ & $\begin{array}{l}\text { This study, Bamfield Inlet } \\
(n=4)\end{array}$ \\
\hline Egregia menziesii & $\begin{array}{l}\text { Demes et al } 2013 \\
(n=39)\end{array}$ & $\begin{array}{l}\text { Starko \& Martone } 2016 \\
(n=5)\end{array}$ & $\begin{array}{l}\text { This study, Scott's Bay } \\
(n=5)\end{array}$ \\
\hline Ecklonia arborea & Hale 2001 & $\begin{array}{l}\text { This study, Scott's Bay } \\
(n=5)\end{array}$ & $\begin{array}{l}\text { This study, Scott's Bay } \\
(n=5)\end{array}$ \\
\hline Cymathaere triplicata & $\begin{array}{l}\text { This study, Ogden } \\
\text { Point }(n=7)\end{array}$ & $\begin{array}{l}\text { This study, Ogden Point } \\
(n=5)\end{array}$ & $\begin{array}{l}\text { This study, Ogden Point } \\
(n=5)\end{array}$ \\
\hline Nereocystis luetkeana & $\begin{array}{l}\text { This study, Botanical } \\
\text { Beach }(n=8)\end{array}$ & $\begin{array}{l}\text { Starko \& Martone } 2016 \\
(n=5)\end{array}$ & $\begin{array}{l}\text { This study, Scott's Bay } \\
(n=3)\end{array}$ \\
\hline Macrocystis pyrifera & Hale 2001 & $\begin{array}{l}\text { Starko \& Martone } 2016 \\
(n=5)\end{array}$ & $\begin{array}{l}\text { This study, Scott's Bay } \\
(n=13)\end{array}$ \\
\hline Postelsia palmaeformis & $\begin{array}{l}\text { This study, Botanical } \\
\text { Beach } \\
(n=8)\end{array}$ & $\begin{array}{l}\text { Starko \& Martone } 2016 \\
(n=5)\end{array}$ & $\begin{array}{l}\text { This study, Cape Beale } \\
(n=3)\end{array}$ \\
\hline Saccharina sessilis & $\begin{array}{l}\text { This study, Botanical } \\
\text { Beach }(n=8)\end{array}$ & $\begin{array}{l}\text { Starko \& Martone } 2016 \\
(n=5)\end{array}$ & $\begin{array}{l}\text { This study, Prasiola Point } \\
(n=7)\end{array}$ \\
\hline Saccharina nigripes & $\begin{array}{l}\text { This study, Scott's } \\
\text { Bay }(n=6)\end{array}$ & $\begin{array}{l}\text { Starko \& Martone } 2016 \\
(n=5)\end{array}$ & $\begin{array}{l}\text { This study, Scott's Bay } \\
(n=12)\end{array}$ \\
\hline Saccharina latissima & $\begin{array}{l}\text { This study, Bamfield } \\
\text { Inlet }(n=4)\end{array}$ & $\begin{array}{l}\text { Starko \& Martone } 2016 \\
(n=4)\end{array}$ & $\begin{array}{l}\text { This study, Bamfield Inlet } \\
(n=6)\end{array}$ \\
\hline Laminaria setchellii & $\begin{array}{l}\text { Starko et al } 2018 \\
\text { (Blowhole) }(n=6)\end{array}$ & $\begin{array}{l}\text { Starko \& Martone } 2016 \\
(n=5)\end{array}$ & $\begin{array}{l}\text { This study, Blowhole } \\
(n=3)\end{array}$ \\
\hline Laminaria ephemera & This study $((n=4)$ & $\begin{array}{l}\text { Starko \& Martone } 2016 \\
(n=5)\end{array}$ & $\begin{array}{l}\text { This study, Edward King } \\
(n=4)\end{array}$ \\
\hline
\end{tabular}




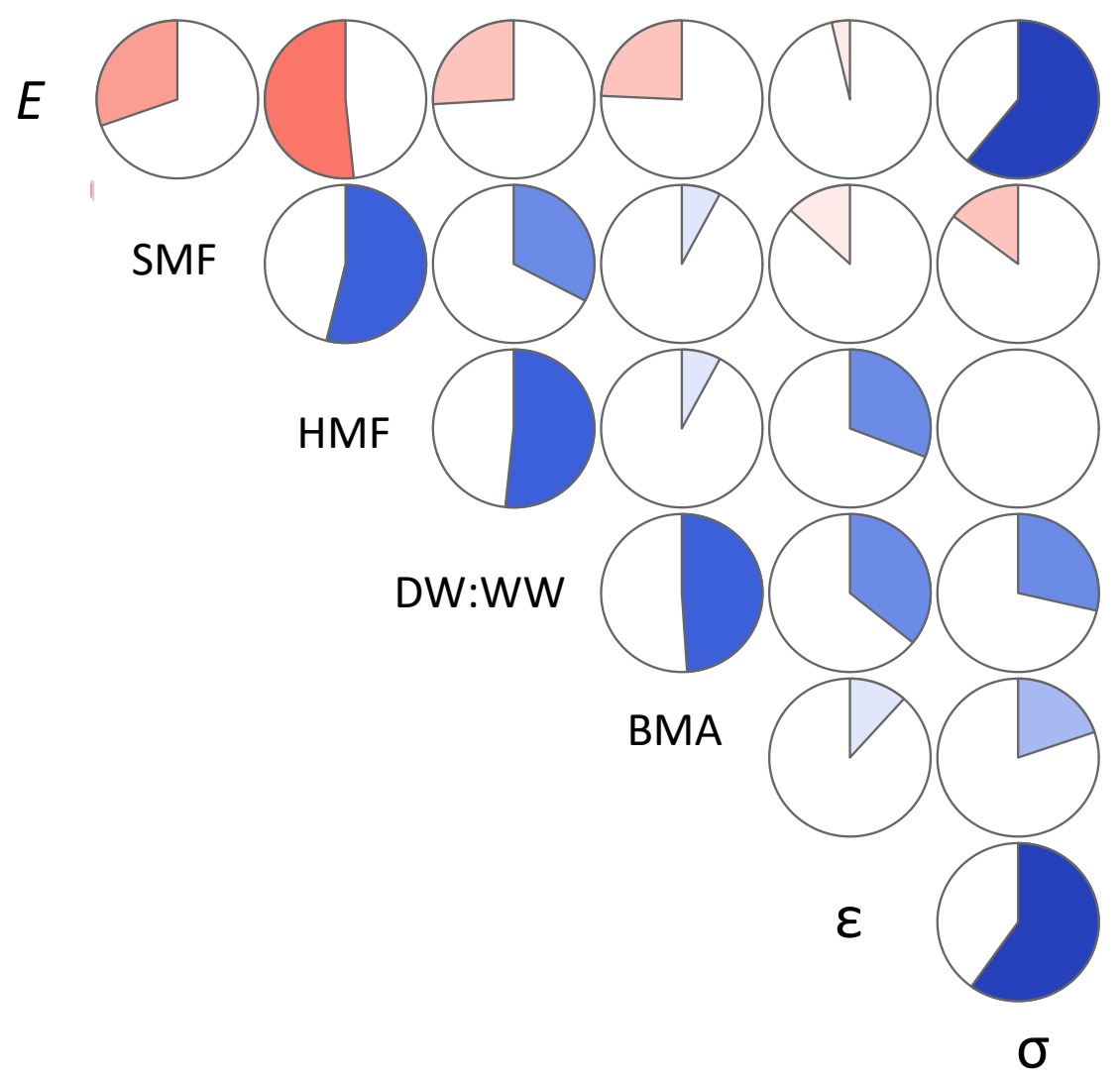

Fig S1. Correlogram of the seven functional traits examined in this study. The filled in pie slices indicate the correlation coefficient, $r(0<r<1)$. Blue slices indicate a positive correlation between traits, while red slices indicate negative correlations. 


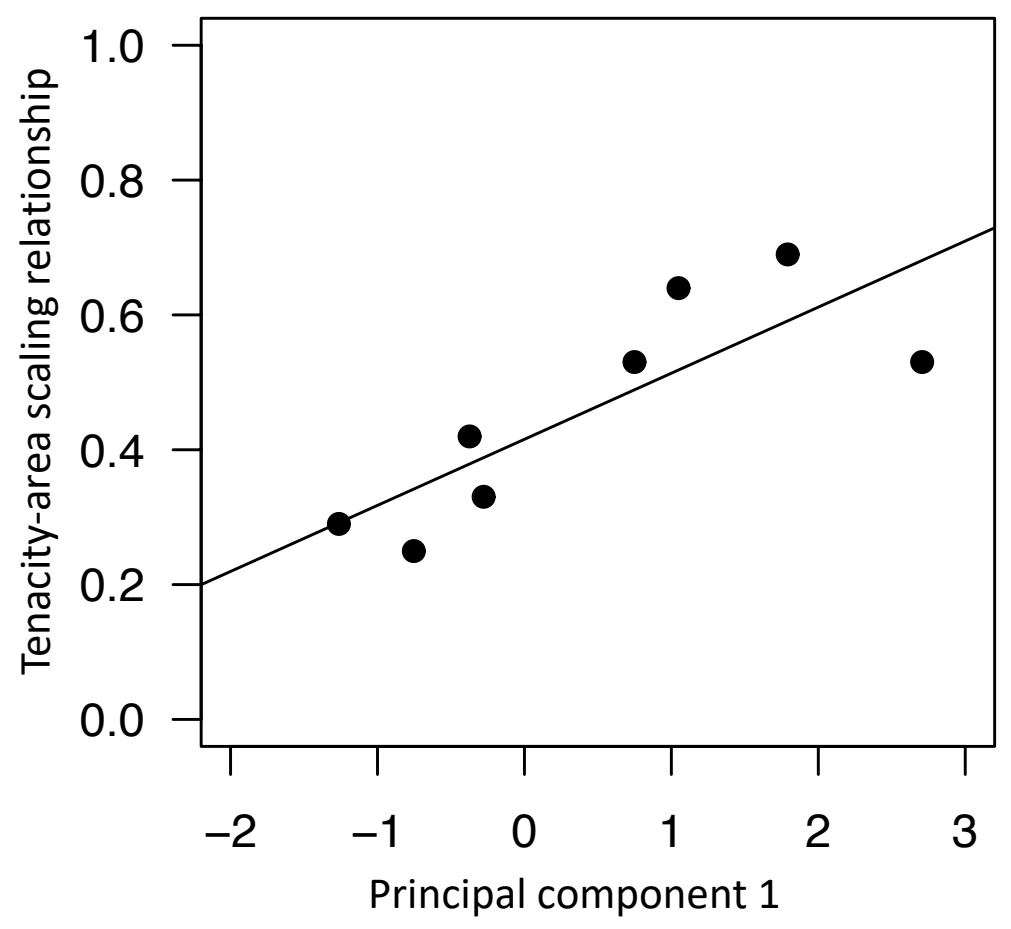

Fig S2. Correlation between principal component 1 (from this study) and tenacity-area scaling relationships (from Starko \& Martone 2016). 

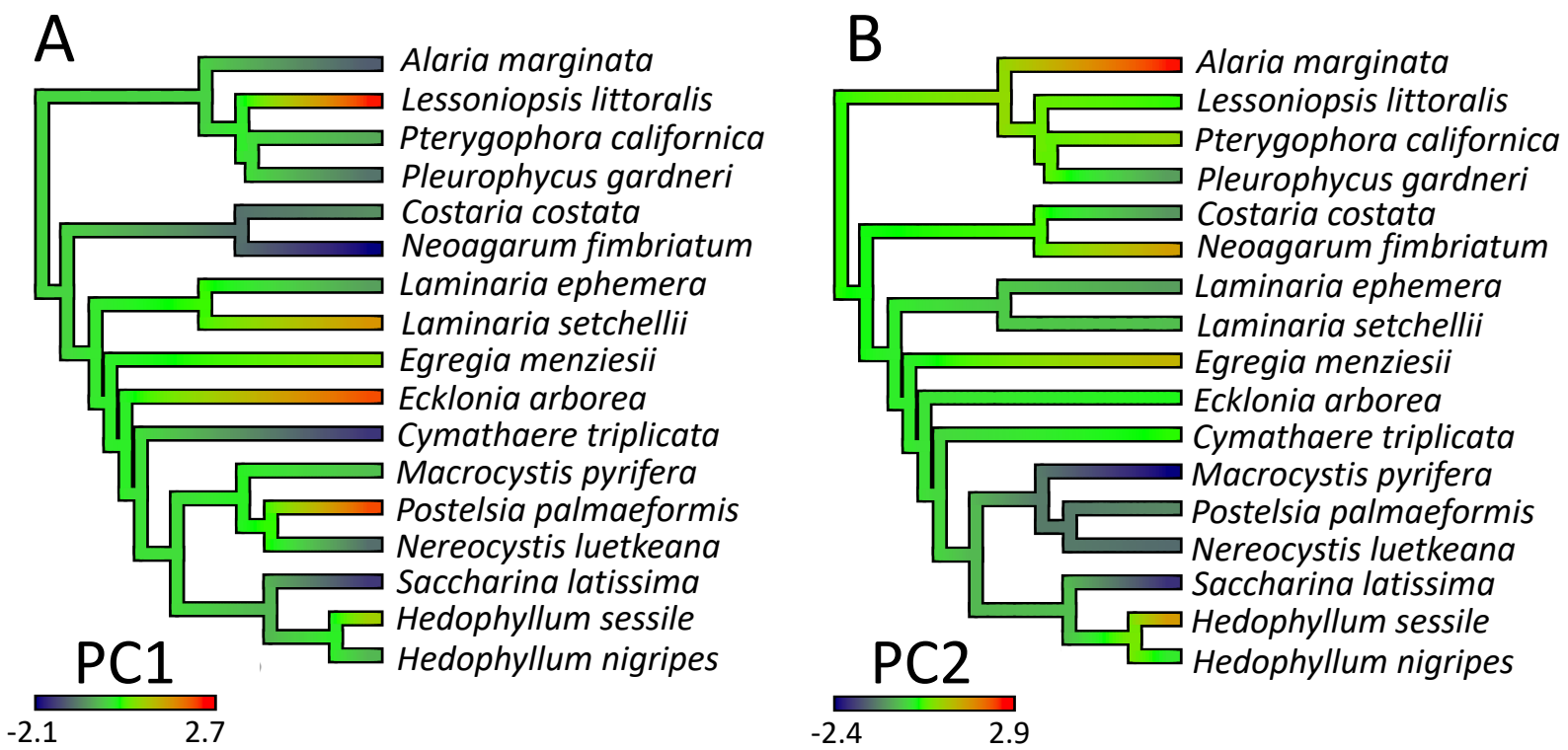

Fig S3. Ancestral state reconstruction of principal components (PC1 and PC2) computed in StableTraits and visualized using contMap. PC1 represents structural reinforcement of the whole kelp thallus, while PC2 represents a component of material properties of the blade.

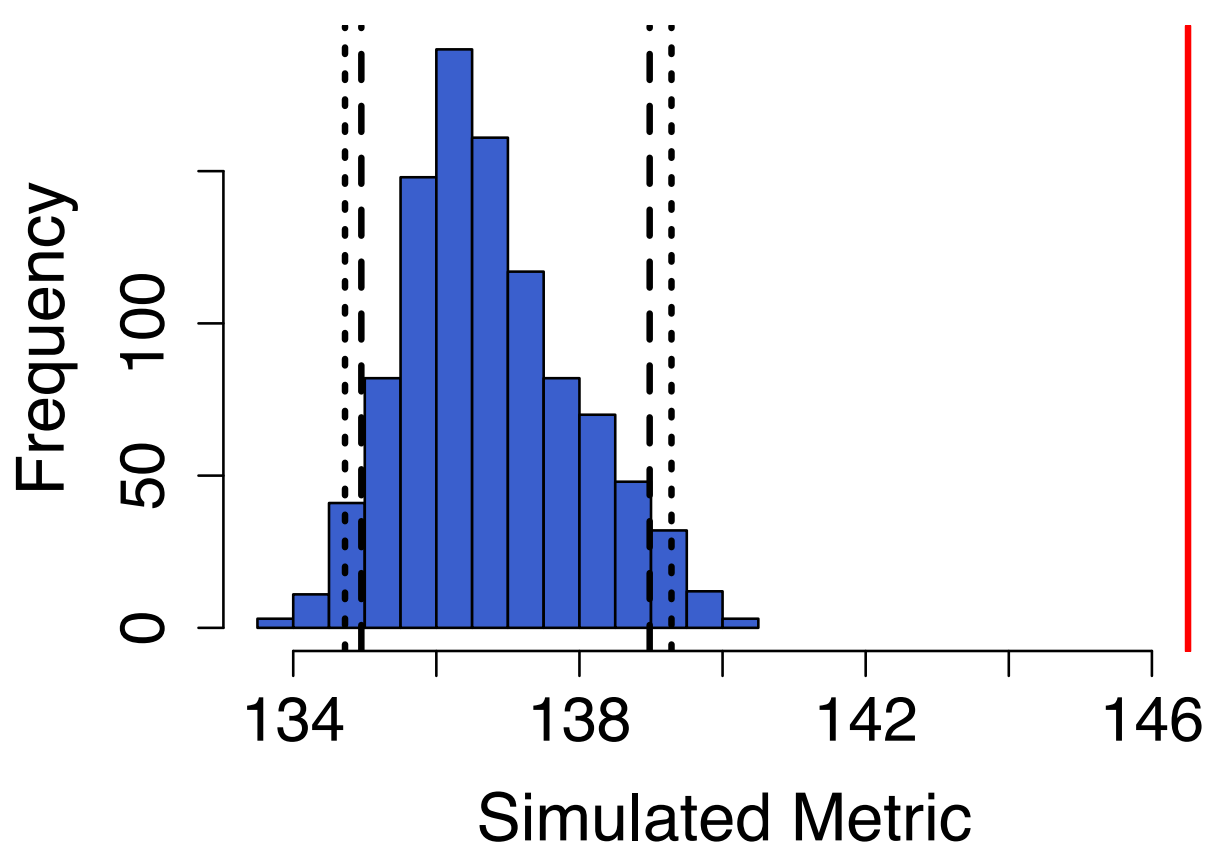

Fig S4. Observed c-score of the community matrix (red line) compared to simulated c-score values from 1000 random communities (blue histogram). Dotted lines indicate $95 \%$ confidence intervals. Analysis was conducted in the package EcoSimR. 


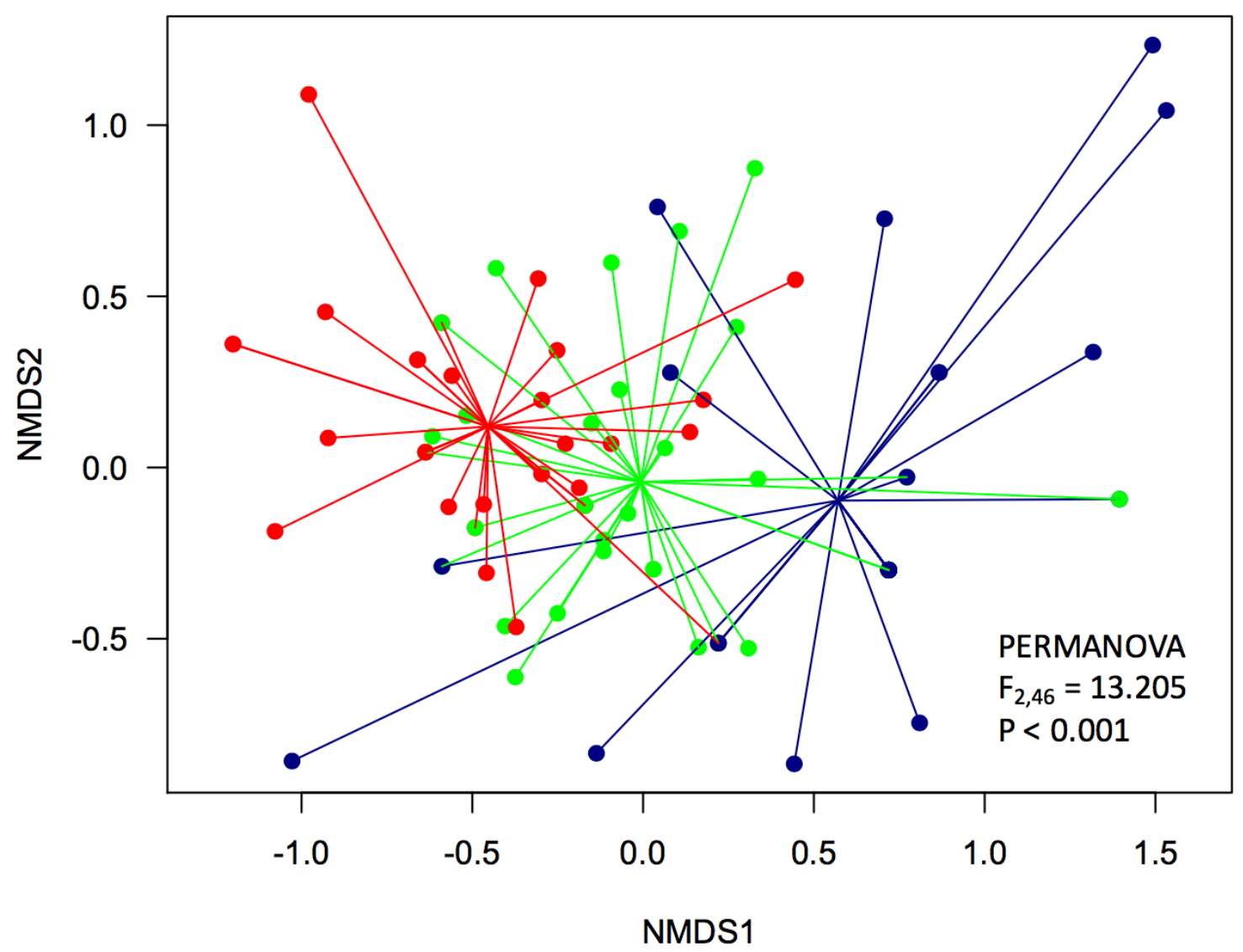

Fig S5 NMDS plot of community presence data for kelp species at 87 sites in Barkley Sound, British Columbia. Sites are coloured by wave exposure category (red $=$ exposed, green $=$ moderate, blue $=$ sheltered $)$ and lines are drawn between all sites and the centroid of its wave exposure category. 